NASA Technical Memorandum 100193

AIAA-87-2692

\title{
On the Correlation of Plume Centerline Velocity Decay of Turbulent Acoustically Excited Jets
}

\author{
(HASA-TM-100193) ON TEE CCERELATICN OF \\ ELUME CENTERLINE VELCCITY CECIY CF TURBULENT \\ N88-16681 \\ ACOUSTICALLY EXCITED JETS (NASA) $35 \mathrm{p}$ \\ $\begin{array}{lll}\operatorname{CSCL} 01 \mathrm{~A} & \mathrm{UnClas} \\ & \mathrm{G} 3 / 02 & 0124580\end{array}$
}

Uwe H. von Glahn

Lewis Research Center

Cleveland, Ohio

Prepared for the

11th Aeroacoustics Conference

sponsored by the American Institute of Aeronautics and Astronautics

Sunnyvale, California, October 19-21, 1987 
ON THE CORRELATION OF PLUME CENTERLINE VELOCITY DECAY OF TURBULENT

\author{
ACOUSTICALLY EXCITED JETS
}

\author{
Uwe H. von Glahn \\ National Aeronautics and Space Administration \\ Lewis Research Center \\ Cleveland, Ohio 44135
}

\title{
SUMMARY
}

Acoustic excitation has been shown to alter the velocity decay and spreading characteristics of jet plumes by modifying the large-scale structures in the plume shear layer. The present work consists of reviewing and analyzing available published and unpublished experimental data in order to determine the importance and magnitude of the several variables that contribute to plume modification by acoustic excitation. Included in the study were consideration of the effects of internal or external acoustic excitation, excitation Strouhal number, acoustic excitation level, nozzle size and flow conditions. The last include jet Mach number and jet temperature. The effects of these factors on the plume centerline velocity decay are then summarized in an overall empirical correlation.

\section{INTRODUCTION}

In recent years, extensive research has been conducted on means to modify or control the decay characteristics of jet plumes. Such means are important for a variety of aircraft/propulsion applications, including jet noise reduction and the design of smaller and lighter nozzle/ejector systems.

Both jet plume decay and spreading rates can be enhanced or reduced by exciting or perturbing the jet shear layer. Such plume excitation can be achieved by acoustic, aero/mechanical, or thermal means. For the most part, excitation of jet plumes to date has been obtained with acoustic means.

With acoustic excitation of the plume, the mechanism involved is phase-locking of the coherent large-scale structure in the plume shear layer with an acoustic signal (ref. 1). The magnitude of the shear layer modification is a primary function of the perturbation strength (acoustic level), jet flow conditions, nozzle size, and acoustic perturbation frequency. Nozzle shape does not appear to be a primary factor since plumes of circular, rectangular, and two-stream nozzles have all been excited with similar plume modification results (refs. 1 to 6 ). Also, the effect of acoustic excitation on a plume appears to be independent of fight speed (ref. 7).

More recently, a model-scale nozzle study (ref. 8) has shown that the boundary layer type (laminar or turbulent) at the nozzle exit is an important parameter for the acoustic excitation of jet plumes. In this and unpublished studies conducted by the Lockheed-Georgia Corporation under NASA contract. jets heated to progressively higher temperatures have shown progressively reduced response to acoustic excitation. This phenomenon can, perhaps be 
attributed to a transition at the nozzle exit plane from a turbulent boundary layer to a transition or laminar boundary layer as the jet temperature was increased. In order to circumvent this phenomenon, a suitable boundary layer trip placed inside the nozzle upstream of the exit plane can be used to provide a turbulent boundary layer at the nozzle exit plane.

The present work presents a new approach to the estimation of plume centerline velocity decay rates of acoustically excited turbulent jets through an empirical correlation of data in terms of parameters known to influence plume centerline velocity decay. The various parameters are first correlated independently and then summed into an overall correlation procedure.

\section{SYMBOLS}

a speed of sound

D nozzle diameter

F plume centerline velocity decay correlation parameter

$L_{e}$ acoustic excitation level, $d B$

Mc local centerline jet Mach number

$M_{j} \quad j e t$ Mach number

$\mathrm{S}_{\mathrm{e}}$ excitation Strouhal number

$S_{e} * S_{e}\left(a_{j} / a_{0}\right)$

$T$ total temperature

$t$ static temperature

$U_{C} \quad$ local jet centerline velocity

$U_{j}$ jet exhaust velocity

$x \quad$ axial centerline distance downstream of nozzle exit plane

Subscripts:

ex excited

j jet

- ambient

p peak

un unexcited 
GENERAL

\section{Flow Considerations}

The primary flow and acoustic excitation parameters that determine the jet plume centerline velocity decay rate for a conic nozzle are summarized schematically in figure 1. The decay data are shown in terms of $U_{c} / U_{j}$ as a function of distance from the nozzle exit plane, $X / D_{j}$. The dashed curves in the figure indicate typical variations or trends away from the basic unexcited curve (solid line). In figure l(a), the effect of an increase in jet temperature is shown to cause a more rapid decay of the plume centerline velocity. In figure $1(b)$, the effect of an increase in jet Mach number is shown to cause a reduction in the plume centerline velocity decay rate with distance downstream of the nozzle exit plane, $X / D_{j}$. With increasing acoustic excitation level, $L_{e}$, the plume centerline velocity decay is shown to increase, as illustrated in figure $1(c)$. Finally, with a constant acoustic excitation level, the plume centerline velocity decay is initially increased with an increase in Strouhal number (based on excitation frequency), $S_{e}, p$, as shown in figure $1(d)$. Further increases in Strouhal excitation number result in lower decay rates that approach the unexcited decay rates and at very high Strouhal excitation numbers decrease the decay rate to less than that for the unexclted rate. The trends shown in figure 1 are independent of the nozzle exit plane shape, although the absolute magnitudes in the decay alteration due to acoustic excitation will differ between nozzle shapes.

\section{Facility Upstream Valve Nolse Effects}

Facllity noise levels, such as valve noise, can affect the plume centerline velocity decay. Data indlcate that such noise has a first order affect on the decay rate as shown in figure 2. The data shown are for a noisy upstream flow control valve position and a quiet valve position. The data shown in the figure are for a jet Mach number of 0.2 , cold flow, and an acoustic sound pressure level of $130 \mathrm{~dB}$ (ref. 6). With a quiet valve position, a peak plume centerline velocity decay, $U_{e x} / U_{u n}$, value of 0.85 at an $x / D_{j}=9$ was measured at an excitation frequency of $550 \mathrm{~Hz}$. With a noisy valve position, a value of only 0.97 was obtained. The difference of 0.12 between the two decay rates was generally maintained over most of the available range of frequencies used in this study. Consequently, a comparison of decay rates from different facilities should consider the noise levels of these facilities in order to provide valid comparisons for excited plume centerline velocity decay characteristics. At this time, such facility nolse validations are not generally available.

\section{Acoustic Sources}

The following section summarizes briefly the two acoustic excitation sources used in the NASA Lockheed studies. In addition, the NASA Lewis source is also summarized.

Internal acoustic excitation sources. - The Lockheed source section used for the acoustic excitation experiments reported in reference 1 utilized four 
electro-acoustic $100 \mathrm{~W}$ Altec drivers. The source section was located in a constant $10.2 \mathrm{~cm}$ diameter pipe section, $6 \mathrm{~m}$ upstream of the nozzle exit plane. In a later series of experiments, the source section was provided with four additional drivers in order to increase the source level. Pairs of acoustic drivers were connected through a "Y" connector to the $10.2 \mathrm{~cm}$ flow duct through four $2.54 \mathrm{~cm}$ diameter tubes to the same location used in reference 1 . Further details of the source section are given in reference 1 .

The NASA Lewis source section also consisted of four acoustic drivers. The acoustic drivers had a rated power of $40 \mathrm{~W}$ over a frequency range of 50 to $20000 \mathrm{~Hz}$. Each driver was connected to an Altec Lansing $100 \mathrm{~W}$ power amplifier. Further detalls of the acoustic source and the facility are given in reference 6 .

External acoustic excitation source. - The eight Altec drivers used by Lockheed for the internal acoustic source studies were also used for the external acoustic source experiments (ref. 8 and unpublished data). For this work the drivers were mounted circumferentially upstream of the nozzle exit plane. Sound was transmitted from the drivers through eight tubes to the nozzle exit plane, with the tubes centered at an $X / D_{j}$ of 0.125 . No-flow calibration measurements were made at the nozzle centerline and at the microphone ring.

\section{Excitation Level Measurement}

Internal acoustic excitation source. - In the NASA Lockheed experiments, the cold-flow excitation levels at the centerline of the nozzle exit plane were measured directly using a microphone fitted with a nose cone. For heated jets, the excitation level was measured indirectly by a twelve-microphone ring placed outside the nozzle but in the plane of the jet exit. The necessary corrections for the two microphone locations were obtained in advance by making simultaneous measurements of the sound levels present at the nozzle exit and the levels at the microphone ring. These calibrations were made for unheated conditions and were assumed to also apply to the heated flows.

In the NASA Lewis studies, the source levels were obtained using a calibrated microphone mounted flush in the nozzle, $0.635 \mathrm{~cm}$ upstream of the nozzle exit plane(ref. 6). Subsequent source level measurements (unpublished) at the centerline in the nozzle exit plane indicated a much lower acoustic source level. A calibration between the original and later microphone locations indicated a $5 \mathrm{~dB}$ lower level for the nozzle exit plane microphone location than that inside the nozzle. Therefore, for a measured internal location acoustic source level of $135 \mathrm{~dB}$ (ref. 6) the measured level at the nozzle exit plane was only $130 \mathrm{~dB}$. As a consequence, all reference 6 data included herein have the reported acoustic excitation levels adjusted by $-5 \mathrm{~dB}$.

External acoustic excitation source. - In considering the effective acoustic excitation level, the distance from the acoustic drivers to the plume shear layer is a primary factor. With internal acoustic excitation, the acoustic levels are generally measured in the plan of the nozzle exit at the nozzle centerline. It has been assumed that the measured levels at this point are constant radially in this plane. With external acoustic excitation, the no-flow acoustic levels were also measured at the nozzle centerline. In 
actuality, however, the acoustic level at the nozzle shear layer is the driver for the large scale turbulence structures in the shear layer that determine the plume decay and spreading rates. For the Lockheed data, the adjustment in the acoustic excitation level from the nozzle centerline to the shear layer location is estimated to be a nominal $3 \mathrm{~dB}$ based on the respective difference in the distances from the source, varying only slightly with jet temperature and flow conditions. Consequently, this amount was added to the measured centerline acoustic levels for all external acoustically excited data included herein.

\section{Nozzle Reynolds Number Considerations}

Consideration of the various effects of acoustic excitation on jet plume decay characteristics suggests that the nozzle boundary layer at the exit plane influences these characteristics. In both the Lockheed and NASA Lewis work, the nozzle Reynolds numbers covered by the data, both published and unpublished, includes all three flow regimes; laminar, transition, and turbulent. In order to establish a common means for comparison of the acoustically excited heated and cold flow plume centerline velocity decay data, the nozzle boundary layer for some of the work was artificially tripped. The intent of the trip being to provide a turbulent boundary layer at the nozzle exit plane over a wide range of jet Mach numbers and temperatures.

Lockheed trips. - In figure 3, several boundary layer wire trips used in the Lockheed studies under contract to NASA are shown in a schematic sketch, together with their location relative to the nozzle exit plane. Of the three trips shown in figure 3 only trip $C$ provided significant improvements in the plume velocity decay characteristics with acoustic excitation over all the flow/temperature conditions of interest in the program.

NASA Lewis trip. - The trip used in the NASA Lewis study, designated trip $D$ herein, consisted of a ring of 82 saw-teeth located about $228.6 \mathrm{~mm}$ upstream of the nozzle exit plane and projecting about $4.76 \mathrm{~mm}$ into the flow. In the present study, this trip was used only with a nozzle having an exit diameter of $5.08 \mathrm{~cm}$.

\section{EFFECT OF NOZZLE BOUNDARY LAYER TRIPS ON PLUME CENTERLINE VELOCITY DECAY}

A comparison of the tripped and untripped external acoustically excited plume centerline velocity decay, $M_{e x} / M_{u n}$, is shown in figure 4 for a range of $S_{e}$ (Ref. 8 and unpublished NASA Lockheed data). The data shown in figure 4(a) are for $a T_{j} / t_{0}$ of $1.0, M_{j}$ of 0.8 , and an $L_{e}$ of $150 \mathrm{~dB}$. In general, the tripped data indicate slightly lower decay rates ( $h i g h e r M_{e x} / M_{u n}$ values) of the order of 0.05 than those of the untripped data; however, this may be within the realm of condition and data repeatability. With a nominal jet temperature ratio, $T_{j} / t_{0}$, of 2.3 , large increases in the plume velocity decay, $M_{e x} / M_{u n}$, as a function of $S_{e}$ were measured when trip $C$ was used as is shown in figure $4(b)$.

A comparison of the centerline velocity decay for nominal $\mathrm{T}_{j} / \mathrm{t}_{0}$ ratios of 1.0 and 2.3 using trip $C$ are shown in figure 5 . The data are also for $a$ 
nominal $M_{j}$ of 0.8 and an acoustic excitation level, $L_{e}$, of $150 \mathrm{~dB}$. In general, the levels of the $M_{e x} / M_{u n}$ are the same for the two temperature ratios; however, at similar values of $M_{e x} / M_{u n}$ the heated data appear to be shifted to somewhat lower $S_{e}$ values than those for the cold flow data.

When the plume velocity decay data are analyzed in terms of an absolute $M_{c} / M_{j}$ rather than a relative $M_{e x} / M_{u n}$ ratio, the apparent benefits resulting from the use of a tripped boundary layer are greatly lessened, particularly for heated flows. With cold flow, the unexcited $M_{c} / M_{j}$ is substantially the same for tripped and untripped nozzle boundary layers, especially at higher jet Mach numbers. Thus, the variation of $M_{c} / M_{j}$ with $S_{e}$ is similar to that previously shown for the variation of $M_{e x} / M_{u n}$ with $S_{e}$. For a heated jet, however, the initial unexcited $M_{c} / M_{j}$ ratio is higher with a tripped nozzle boundary layer than that with an untripped boundary layer as shown in figure 6. Consequently, the apparent benefits in the decay rates shown in figure 4 are not realized when $M_{c} / M_{j}$ is considered. The data shown in figure 6 indicate that the maximum absolute plume centerline velocity decay rate due to acoustic excitation is substantially at the same level whether or not a nozzle boundary layer is tripped in the presence of heated flow. For an $M_{j}$ of 0.3 , boundary layer trip $C$ caused a slightly higher $M_{c} / M_{j}$ value for unexcited flow than that without the tip; however, with heated flow results similar to those discussed for an $M_{j}$ of 0.8 were obtained.

A comparison of plume centerline velocity decay trends for tripped and untripped boundary layer data is shown in figure 7 in which the measured unexcit$\frac{\text { ed }}{x / D} M_{c} / M_{j}$ ratios are plotted a function of $x\left(t_{j} / t_{0}\right) 0.25 / D_{j}\left(1+M_{j}\right) 0.5$ at an $\overline{X / D_{j}}$ of 9 . Also shown in the figure is the centerline velocity decay curve for unexcited flow taken from reference 2. Except for the heated tripped flows, all the data are well represented by the curve. The heated tripped data yield higher $M_{c} / M_{j}$ values than the heated untripped data at the same operating conditions. At this time no explanation for this behavior is available. Similar data trends to those discussed above were also obtained, based on very limited data, in unpublished NASA Lewis using trip D and unexcited cold flow.

Finally, a summary cartoon of the data trends discussed in this section is shown in figure 8 for tripped and untripped nozzle boundary layer conditions.

\section{CORRELATION PARAMETER F}

The plume centerline velocity decay with acoustic excitation was correlated in terms of a parameter herein designated by $F$. In figure $9(a)$, the centerline velocity decay curve (untripped nozzle boundary layer) for a typical unexcited jet plume (ref. 2) is shown schematically in terms of $U_{c} / U_{j}$ as a function of $x\left(t_{j} / t_{0}\right) 0.25 / D_{j} \sqrt{1+M_{j}}$. With acoustic excitation, this curve shifts progressively to the left on the abscissa with increasing acoustic excitation levels as indicated in figure 1. The data included herein were all obtained at an $X / D_{j}$ of 9.0 . Two schematic representative data points, one for cold flow and one for heated flow are al so shown in figure $g(a)$. The correlation parameter $F$ is defined as the factor required to shift an acoustically excited data point (or curve) to the unexcited decay curve. 
With a tripped nozzle boundary layer the reference unexcited velocity decay curve can be shifted to the right of the untripped nozzle boundary layer velocity decay curve as shown in figure $9(b)$. Consequently, $F$ as presently defined must be measured from the shifted unexcited velocity decay point or curve when a tripped nozzle boundary layer is used, particularly with heated flows.

\section{DATA BASE}

Representative data plots of the correlation parameter, $F$, as a function of the Strouhal excitation number, $S_{e}$, are shown in figures 10 to 14 .

\section{External Acoustic Excitation}

Untripped nozzle boundary layer. - The variation of $F$ with $S_{e}$ using external acoustic excitation is shown in figure 10 for a jet Mach number of 0.8 , an $L_{e}$ of 147 and $150 \mathrm{~dB}$, and temperature ratios, $T_{j} / t_{0}$, of 1.0 and 2.32 . The data shown are for repeat test runs and indicate the degree of data repeatability. With a heated jet and an untripped nozzle boundary layer, the acoustic excitation effect on the plume velocity decay is significantly reduced for equal levels of excitation and the peak $F$ value occurs at a lower $S_{e}$. The significance of this phenomenon will be discussed in more detail later.

Tripped nozzle boundary layer. - The data with an untripped nozzle boundary layer indicated some anomalies between high and low jet Mach numbers with acoustically excited plumes. It was considered possible that the presence of a nozzle exit laminar boundary layer could provide plume velocity decay characteristics different from those with a turbulent boundary layer. Consequently, several boundary layer trips were used upstream of the nozzle exit plane in order to provide a turbulent boundary layer at the nozzle exit with low jet Mach number flows. In figure 11 the variation of $F$ with $S_{e}$ using trip $C$ is shown for the same temperature and acoustic excitation levels given in figure 10 and nominal $M_{j}$ values of 0.3 and 0.8 . It is apparent that the values of $F$ for the heated plumes are now at about the same level as those with cold flow; however, the heated data are still shifted to the left, on the abscissa, of those for cold flow. This was also the case for the untripped data shown previously in figure 10 .

\section{Internal Acoustic Excitation}

Untripped nozzle boundary layer. - The variation of $F$ with $S_{e}$ using an internal acoustic excitation source is shown in figures 12 and 13 . The data shown in figure 12 are for jet Mach numbers of 0.3 and 0.8 and temperature levels, $T_{j} / t_{0}$, of 2.74 and 1.65 , respectively, as well as for cold flow. The acoustic excitation level for these points was not quite constant, ranging from 145 to $150 \mathrm{~dB}$ for each data set. The temperature effect is not as apparent for the $M_{j}=0.3$ data, but still appears to be present, particularly at the highest $S_{e}$ values. In general, however, the data trends are similar to those obtained with external excitation. 
In figure 13 are shown representative data reported in reference 6 . The data shown are for a nozzle diameter of $8.89 \mathrm{~cm}, M_{j}$ of 0.435 , Le of $130 \mathrm{~dB}$, and cold flow. Data similar to that shown in figure 13 were also obtained with an $L_{e}$ of $125 \mathrm{~dB}$.

Tripped nozzle boundary layer. - A brief study was also made as part of the NASA Lewis research effort to evaluate the effect of nozzle size on acoustically excited nozzle plume velocity decay. The combination of a $5.08 \mathrm{~cm}$ diameter nozzle and cold flow resulted in a laminar boundary layer at the nozzle exit plane. In order to provide a turbulent boundary layer for comparison with other data, the nozzle boundary layer was tripped using trip $D$. The results for the untripped and tripped boundary layers in terms of $F$ as a function of $S_{e}$ are shown in figure 14 for an $L_{e}$ of $125 \mathrm{~dB}$, an $M_{j}$ of 0.435 , and cold flow. It is apparent that higher levels of $F$ were obtained with the trip.

\section{PERIODIC NATURE OF DATA}

The available excited plume data suggest that the variation of $F$ with $\mathrm{S}_{e}$ is periodic or cyclic in nature, resulting in a series of peak $F$ values separated by valleys of low $F$ values. Such representations are shown schematically in figure 15. The peak $F$ values are closely spaced at low $S_{e}$ values and this spacing becomes increasingly wider as $\mathrm{S}_{e}$ is increased. The data shown in figure 15 are for internal acoustic excitation of the plume. Similar effects (not shown) were noted for external acoustic excitation of the plume. Consequently, some data obtained at a given Strouhal number for both internal and external acoustic excitation may not be at a peak $F$ value.

\section{PLUME TEMPERATURE CONSIDERATIONS}

The effect of jet temperature level on the plume centerline velocity decay with acoustic excitation was apparent in figures 10 to 14 . In order to correlate cold and heated jet flows, both the correlation parameter $F$ and the Strouhal excitation number, $S_{e}$, require a temperature correlation parameter. In this section, only the strouhal excitation number will be considered.

Based on the available data, it appears that the Strouhal excitation number must include a temperature term given by $\left(t_{j} / t_{0}\right) 0.5$. Herein, this factor is expressed in terms of the acoustic speed at the nozzle exit plane to that of the surrounding ambient air; namely $a_{j} / a_{0}$. Typical plots of $F$ as a function of $S_{e}$, with and without the aj/ao parameter are shown in figure 16.

In figure 17, the variation of $F$ with $S_{e}\left(a_{j} / a_{0}\right)$ hereinafter designated by $S_{e}{ }^{*}$, is shown for a jet Mach number of 0.8 , temperature ratios, $T_{j} / t_{0}$, of 1.0 and 2.3 , and both untripped and tripped nozzle boundary layers. Only the data for the untripped heated flow deviates markedly from the other cases. Thus, when the nozzle boundary layer is properly tripped to provide a turbulent layer, substantially similar $F$ values are obtained as a function of $\mathrm{S}_{e}{ }^{*}$. However, as pointed out earlier, in terms of absolute values, the apparent benefits due to tripping may not be realized because the unexcited jet velocity ratio at a given $X / D_{j}$ can be higher when the flow is tripped than when the flow is not tripped. 
In comparing the acoustically excited NASA Lewis low Mach number data with similar Lockheed data at a higher Mach number (Fig. 18), the displacement of the two data sets was initially believed to be possibly due to the difference in nozzle diameter $(8.89 \mathrm{~cm}$ and $5.08 \mathrm{~cm}$, respectively). In order to verify this consideration, a set of data were obtained in the NASA Lewis facility with a $5.08 \mathrm{~cm}$ nozzle and compared with that for the larger nozzle. With the smaller nozzle both tripped and untripped data were obtained. These data are shown in figure 19 together with that for the larger nozzle. The data shown were all obtained with an $M_{j}$ of 0.435 , an $L_{e}$ of $125 \mathrm{~dB}$, and cold flow. It is apparent that the nozzle diameter difference is not the cause of the data shift noted in figure 18 since the turbulent boundary layer data for the two different nozzle diameters coincide. As expected, the tripped data with the smaller nozzle provided higher $F$ values than those with the tripped boundary layer.

From these data, it appears that the cause of the data shift shown in figure 18 was not due to the nozzle diameter difference. Instead, it was then assumed that the cause for the data shift was due to the differences in the acoustic excitation levels. This assumption was corroborated by subsequent studies using an external acoustic excitation source (ref. 8 and unpublished NASA Lockheed data) and will be discussed and illustrated in detail later.

\section{CORRELATION OF ACOUSTICALLY EXCITED PLUME VELOCITY DECAY DATA}

The available published and unpublished data indicate that with a constant acoustic excitation level, correlation envelope curves could be constructed that would pass through an apparent peak $F$ as a function of $S_{e}{ }^{*}$. Such curves are shown schematically in figure 20. Initially, at an $\mathrm{Se}^{*}$ of 0 , the curves have an $F$ value of 1.0 (unexcited flow). With increasing values of $S_{e}{ }^{*}, F$ also increases, reaching a peak value at an $S_{e, p}$. This latter parameter is a function of the acoustic excitation level, $L_{e}$, and the plume static temperature $t_{j}$. The value of $F$ then decreases with further increases in $S_{e}{ }^{*}$. At $S_{e}^{*}$ values greater than $2, F$ becomes less than 1.0, indicating that the plume velocity core is no longer being decayed by acoustic excitation but is being elongated. Furthermore, the peak $F$ value, $F_{p}$, occurs at larger $\mathrm{S}_{\mathrm{e}}{ }^{*}$ values with decreasing levels of $\mathrm{L}_{e}$ (Fig. 20).

The data also indicate a difference in the decay effect depending on whether internal or external excitation sources are used. Although the reason for this difference is not known presently, it is possible that the acoustic signal interaction with the jet shear layer has different effects depending on whether the acoustic signal approaches the outer or inner boundary of the plume shear layer.

\section{Correlation of $F_{p}$}

External excitation. - Using the acoustic excitation levels at the plume shear layer, the following equation for $F_{p}$ was developed and includes consideration of $L_{e}$ and the static temperature ratio, $t_{j} / t_{0}$ : 


$$
F_{p}=1+\left[\left(170.6 / L_{e}\right)^{7.7}-1\right]^{-1.0}\left[1-\left(\frac{t_{j} / t_{0}}{2.125}\right)^{2.15}\right]^{0.5}
$$

Internal acoustic excitation. - In a similar correlation procedure to that used for the external excitation case, the following equation was developed for internal acoustic excitation of the plume:

$$
F_{p}=1+\left[\left(167.6 / L_{e}\right)^{7.25}-1\right]^{-1.0}\left[1-\left(\frac{t_{j} / t_{0}}{2.125}\right)^{2.15}\right]^{0.5}
$$

Note that both the reference acoustic level (167.6) and its exponent are different in equation (2) than in equation (1).

A second equation for $F_{p}$ was also considered that yields substantially similar results in the range of the available data that has only one change from the external excitation case; namely, in the reference acoustic level, as follows:

$$
F_{p}=1+\left[\left(165.6 / L_{e}\right)^{7.7}-1\right]^{-1.0}\left[1-\left(\frac{t_{j} / t_{o}}{2.125}\right)^{2.15}\right]^{0.5}
$$

Additional data are needed to determine which equation, (2) or (3), provides better correlation at higher acoustic excitation levels than those presently available.

$$
\text { Correlation of } S_{e, p}^{*}
$$

External acoustic exciations. - The correlation of the Strouhal number associated with $F_{p}$ is given by the following equation:

$$
S_{e, p}^{*}=2\left[1-\left(L_{e} / 170.6\right)^{3.33}\right]^{1.645}
$$

Internal acoustic excitation. - As in the correlation of $F_{p}$, the correlation of $S_{e, p}^{*}$ differs slightly from that for external acoustic excitation. Also, two equations are included that depend on the reference acoustic level. The two equations are given by the following relations:

$$
S_{e, p}^{*}=2\left[1-\left(L_{e} / 167.6\right)^{3}\right]^{1.85}
$$


or

$$
S_{e, p}^{*}=2\left[1-\left(L_{e} / 165.6\right)^{3}\right]^{1.75}
$$

Equation (5) should be used with equation (2) and, similarly, equation (6) should be used with equation (3).

\section{Off-Peak F Calculations}

The procedure for calculating off-peak values of the parameter $F$ depends on whether the $S_{e}^{*}$ values are less or greater than $S_{e, p}^{*}$.

$S_{e}{ }^{*} \leq S_{e}^{*}, p^{*}$ - The following equation is used to calculate the envelope curve (peak values) of $F$ as a function of $S_{e}{ }^{*}$ for values less than $S_{e, p}{ }^{*}$ :

$$
F_{1}=1+\left(F_{p}-1\right)\left(S_{e}^{*} / S_{e, p}^{*}\right)^{3.0}
$$

$S_{e}^{*} \geq S_{e, p}^{*}$ - For $S_{e}^{*}$ values greater than $S_{e, p}^{*}$, the envelope curve for $F$ is calculated by the following equation:

$$
F_{2}=1+\left(F_{p}-1\right)\left(S_{e, p}^{*} / S_{e}{ }^{*}\right)^{n}
$$

where

$$
n=\log \left(F_{p}\right)^{-1} / \log 0.5\left(S_{e, p}^{*}\right)
$$

COMPARISON OF DATA WITH CALCULATED ENVELOPE CURVES

In figures 21 to 25 are shown representative acoustically excited plume velocity decay data in terms of $F$ as a function of $S_{e}{ }^{*}$ together with calculated envelope curves based on the equations developed in the preceding sections. In general, considering the periodic nature of the excitation phenomenon discussed earlier, good agreement between the data and the correlation curves have been obtained for all cases.

\section{CONCLUDING REMARKS}

Data obtained at $M_{j}$ of 0.3 (unpublished NASA Lockheed data) for which both cold and heated flows at the nozzle exit were in the laminar boundary regime suggest that the temperature effects on the plume decay are significantly different than those associated with turbulent boundary layers. Limited data obtained with internal acoustic excitation show that the local $F$ 
values with $\mathrm{S}_{e}{ }^{*}$ are higher with heated flow than cold flow at similar excitation levels, as shown in figure 26. These data suggest that if the boundary layer at the nozzle exit is decreased or removed, i.e., bled off, heated jet plumes could perhaps be excited to $F$ values equal or greater than those for cold flows without encountering the unexcited plume velocity decay penalties associated with tripped nozzle boundary layers.

\section{CONCLUSIONS}

On the basis of the avallable data and the results of the present analysis of internal and external acoustically excited jet plumes the following conclusions are made concerning the effect of acoustic excitation on the plume centerline velocity decay characteristics:

1. Equations were developed to estimate the jet centerline velocity decay changes caused by:

a. excitation Strouhal number

b. jet temperature level

c. acoustic excitation level

2. An increase in acoustic excitation level is accompanied by a decrease in the frequency at which the peak plume centerline velocity decay occurs.

3. The analysis of the data indicate that the nozzle boundary layer is a factor in determining the acoustic excitation effects on the plume centerline velocity decay.

4. With a naturally developed nozzle boundary layer (untripped), increasing the jet temperature caused a significant reduction in the effectiveness of acoustic excitation on the plume centerline velocity decay relative to that for turbulent cold flow jets.

5. With an artificially tripped nozzle boundary layer, the plume centerline velocity decay with cold or heated flows was substantially the same at the same acoustic excitation level.

6. Artificial tripping of the nozzle boundary layer caused an increase in the unexcited local centerine velocity decay ratio, particularly with heated flows.

7. In terms of absolute local plume centerline velocity decay obtained with acoustic excitation, no apparent benefits were obtained by tripping the nozzle boundary layer compared with untripped values over the range of conditions included by the data.

8. The variation of the plume centerline velocity decay with acoustic excitation as a function of excitation Strouhal number appears to be periodic in nature; consequently much of the available data are off-peak values of the correlation parameter $F$ for a given Strouhal excitation number, in particular that obtained with internal acoustic excitation. 


\section{REFERENCES}

1. Ahuja, K.K., Lepicovsky, J., Tam, C.K.W., Morris, P.J., and Burrin, R.H., "Tone-Excited Jet: Theory and Experiments," NASA CR-3538, 1982.

2. von Glahn, U., "On Some Flow Characteristics of Conventional and Excited Jets," AIAA Paper 84-0532, Jan. 1984. (NASA TM-83503).

3. von Glahn, U., "Preliminary Analysis of Tone-Excited Two-Stream Jet Velocity Decay," NASA TM-86951, 1985.

4. Bechert, D.W., "Excitation of Instability Waves," Zeitschrift fuer Flugwissenschaft und Weltraumforschung, Vol. 9, No. 6, Nov.-Dec. 1985, pp. 356-361.

5. Lu, H.Y., "Effect of Excitation on Coaxial Jet Noise as Observed by an Elliptic Mirro," AIAA Paper 81-2044, Oct. 1981.

6. Raman, G. and Ghorashi, B., "Enhanced Mixing of an Axisymmetric Jet by Aerodynamic Excitation," NASA CR-175059, 1986.

7. von Glahn, U., "Correlation of Flight Effects on Centerline Velocity Decay for Cold-Flow Acoustically Excited Jets," NASA TM-83502, 1983.

8. Lepicovsky, J. and Brown, W.H., "Effects of Nozzle Exit Boundary Layer Conditions on Excitability of Heated Free Jets," AIAA 87-2723, Oct. 1987. 


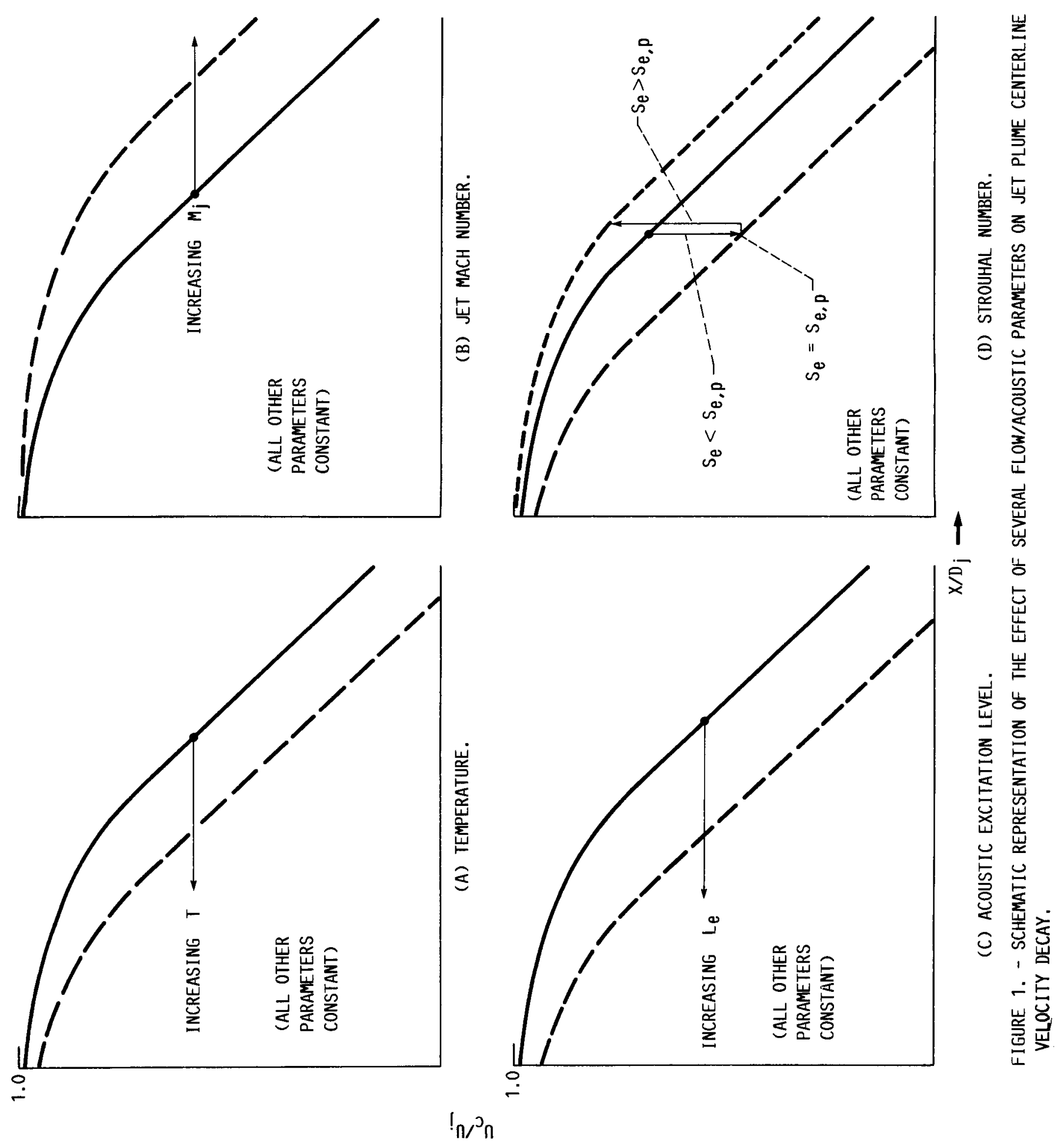




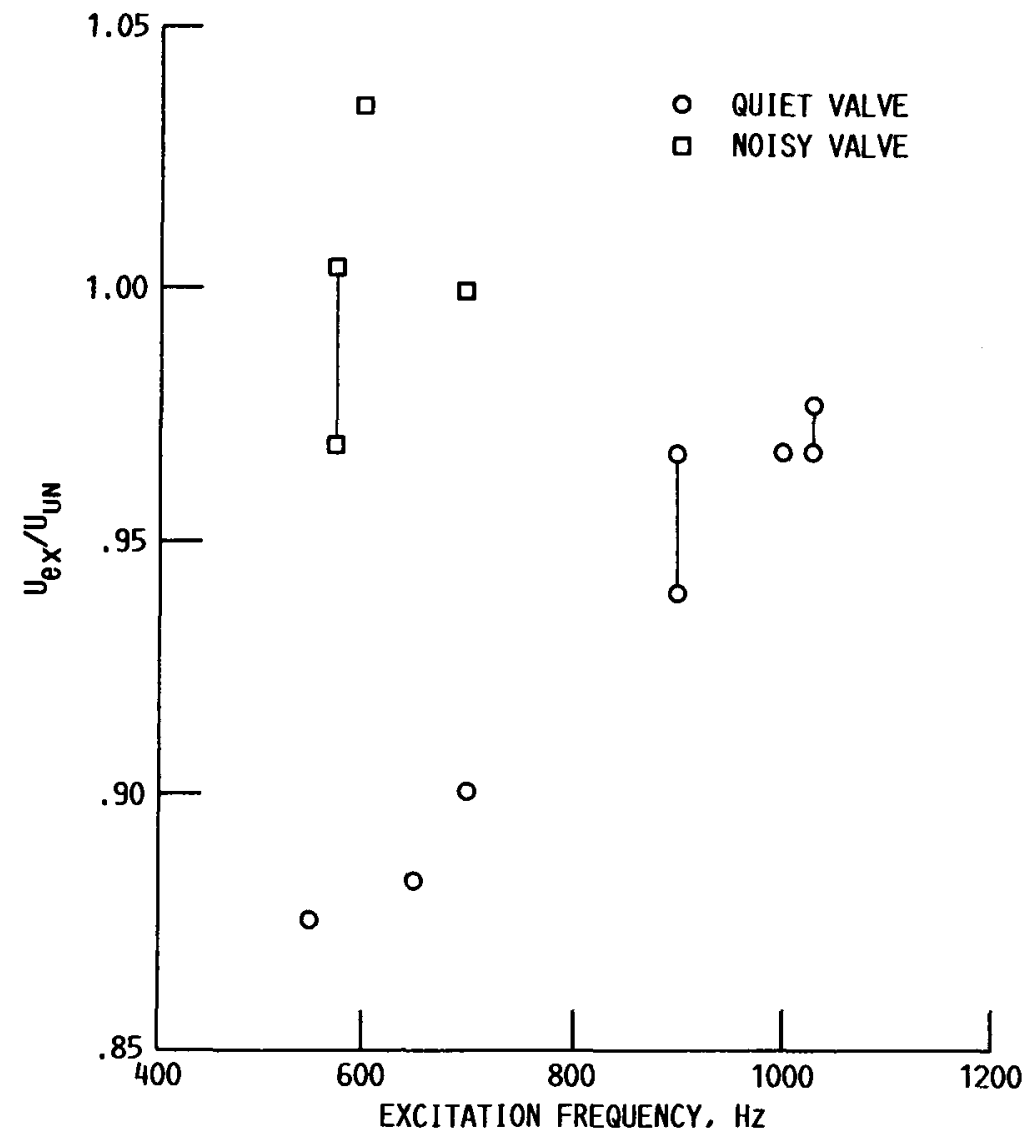

FIGURE 2. - EFFECT OF FACILITY VALVE NOISE ON EXCITED PLUME CENTERLINE VELOCITY DECAY. REFERENCE 6;

$\mathrm{M}_{\mathrm{j}} \cdot 0.2: \mathrm{L}_{\mathrm{e}} \cdot 130 \mathrm{~dB}$; COLD FLOW.

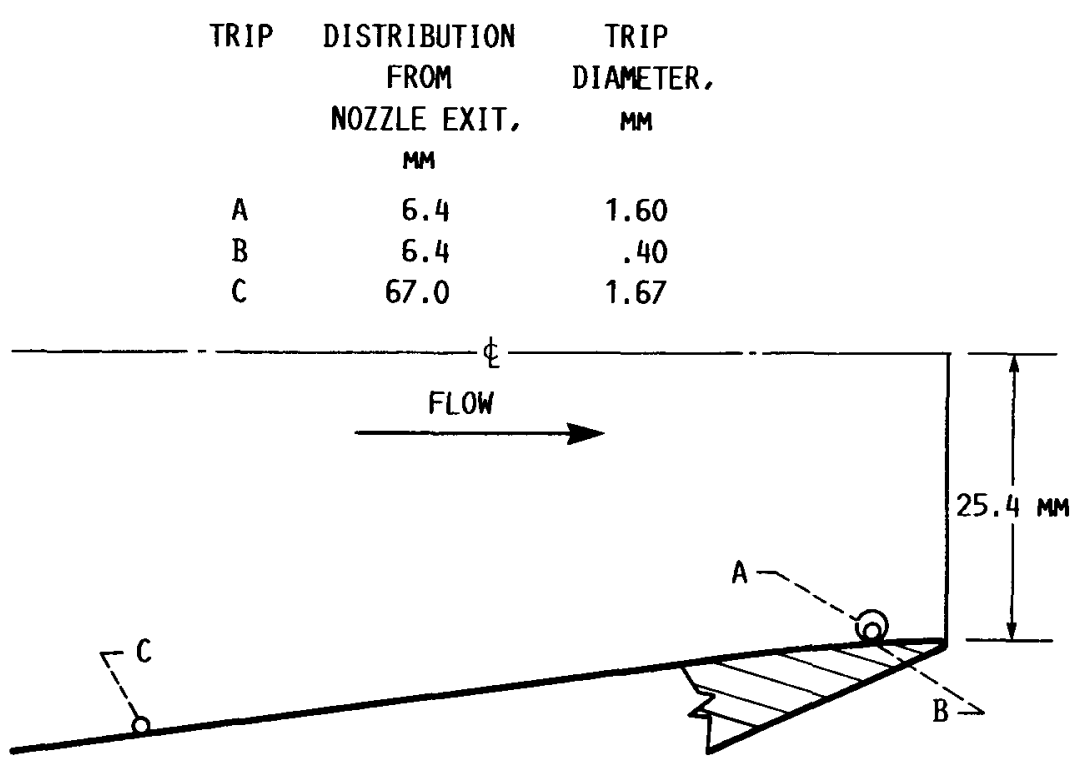

FIGURE 3. - SCHEMATIC SKETCH OF NOZZLE BOUNDARY LAYER TRIP LOCATIONS AND DIMENSIONS. 


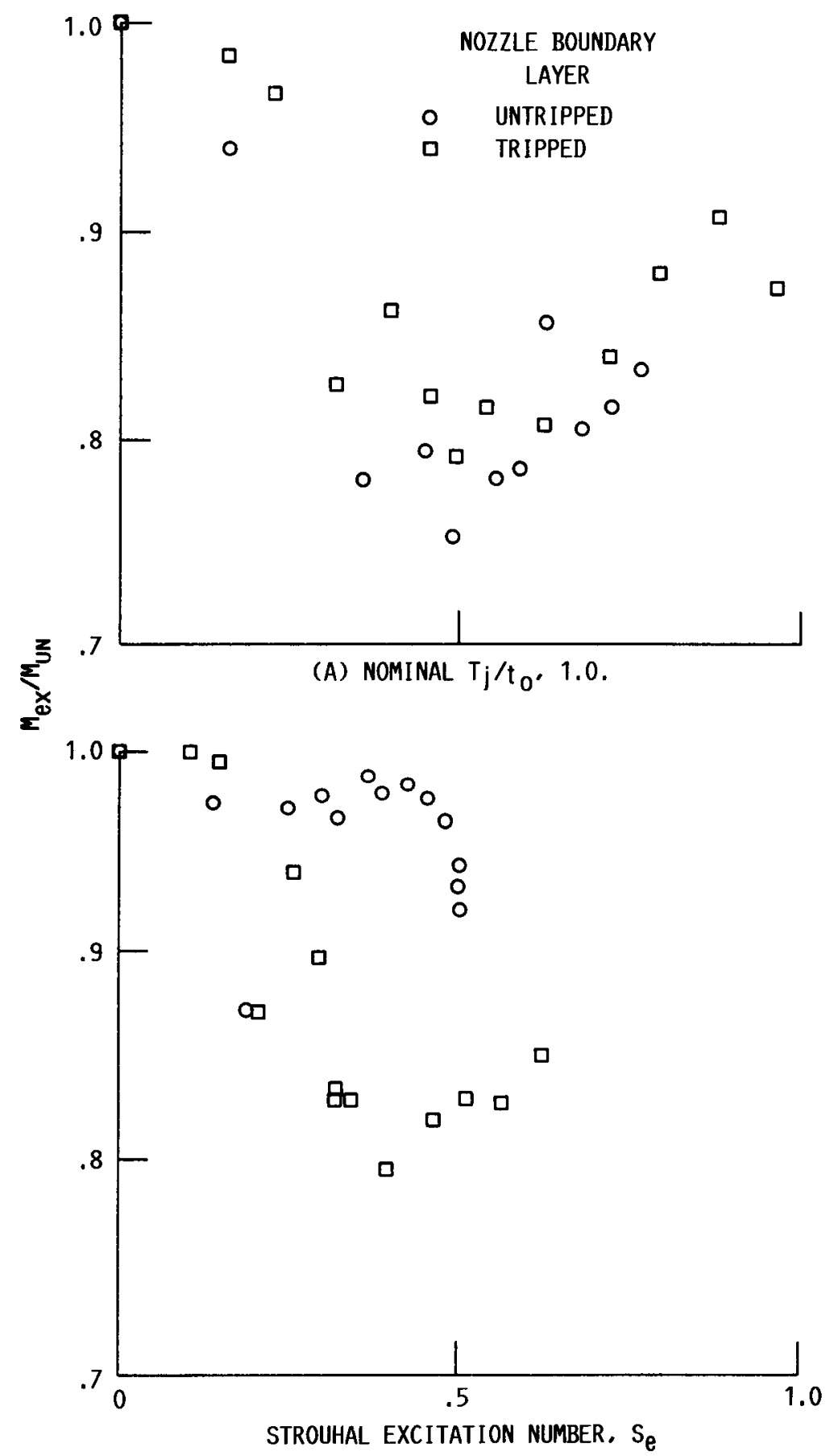

(B) NOMINAL $\mathrm{T}_{j} / \mathrm{t}_{0}, 2.3$.

FIGURE 4. - EFFECT OF NOZZLE BOUNDRY LAYER TRIP ON PLUME CENTERLINE VELOCITY DECAY FOR VARIOUS STROUHAL NUMBERS. TRIP $\mathrm{C}$ : $\mathrm{L}_{\mathrm{e}}, 150 \mathrm{~dB}$; NOMINAL $\mathrm{Mj}, 0.8$; EXTERNAL ACOUSTIC EXCITATION: X/D, 9. 


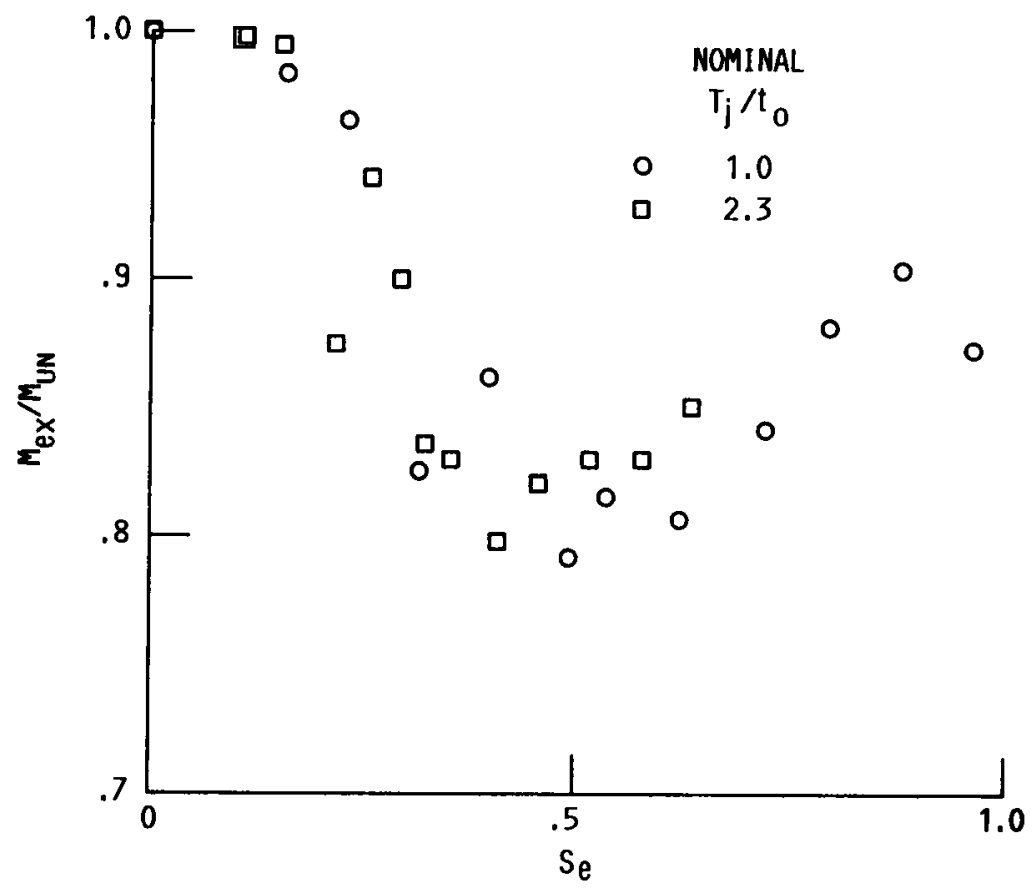

FIGURE 5. - COMPARISON OF PLUME CENTERLINE VELOCITY DECAY FOR TWO JET TEMPERATURES AND VARIOUS STROUHAL NUMBERS. TRIPPED NOZZLE BOUNDARY LAYER (C): $M_{j}, 0.8 ; L_{e}, 150 \mathrm{~dB}$; EXTERNAL ACOUSTIC EXCITATION, X/Dj, 9.

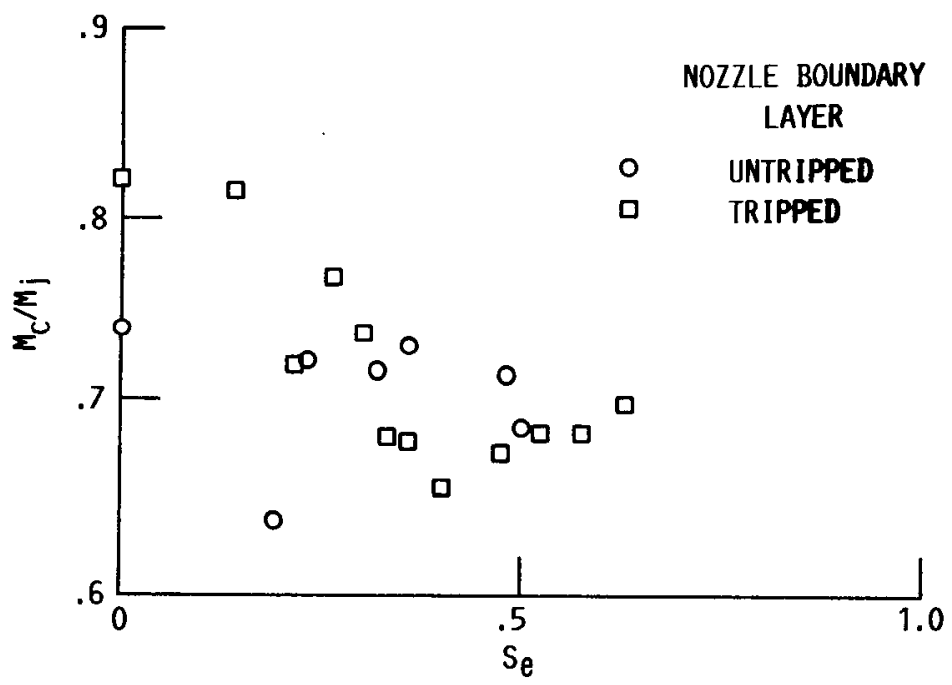

FIGURE 6. - COMPARISON OF HEATED PLUME CENTERLINE VELOCITY DECAY, $M_{C} / M_{j}$. AS A FUNCTION OF $S_{e}$ FOR TRIPPED AND UNTRIPPED NOZZLE BOUNDARY LAYERS. TRIP $C$; NOMINAL $M_{j}, 0.8 ;$ NOMINAL $T_{j} / t_{0}, 2.33$; $X / D_{j}, 9 ; L_{e}, 150 \mathrm{~dB}$. 


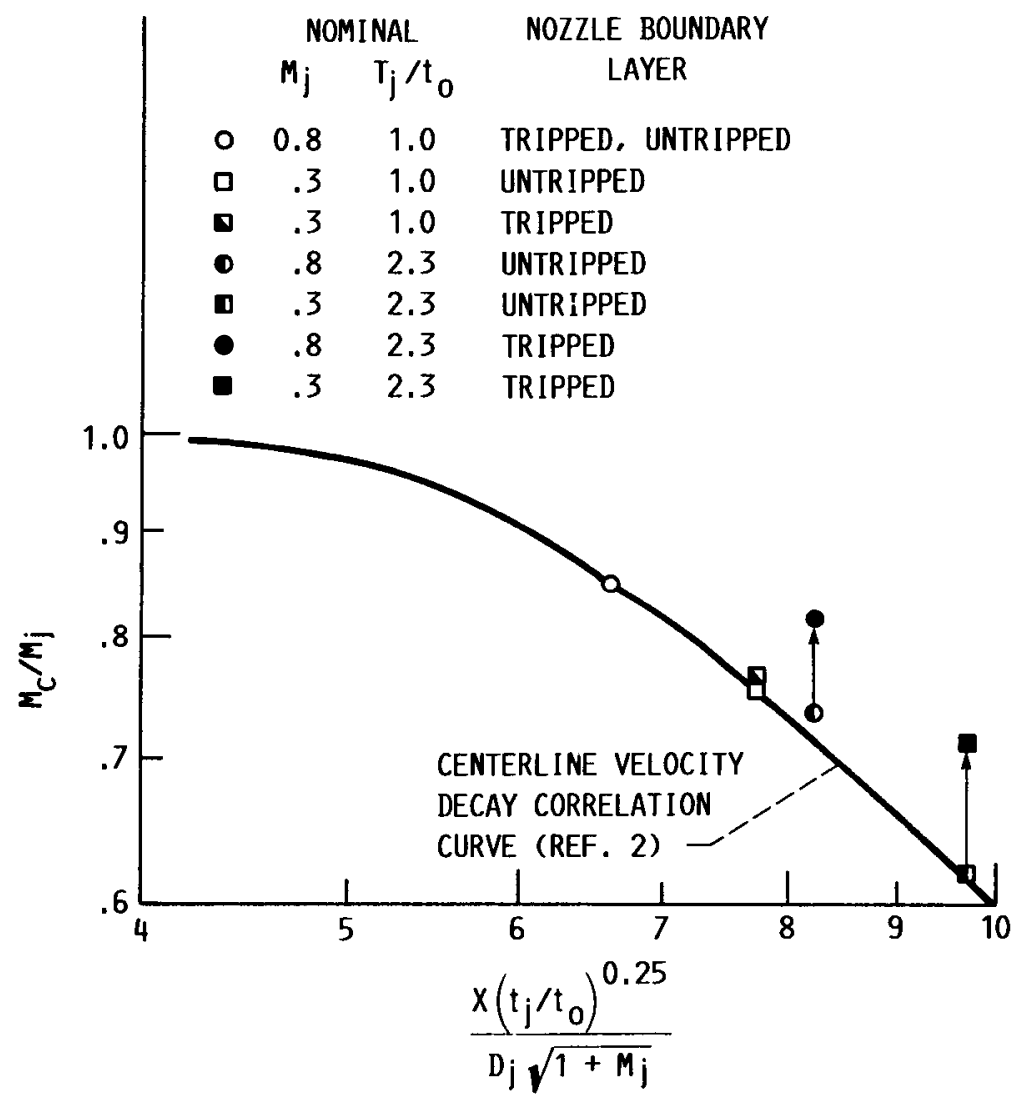

FIGURE 7. - COMPARISON OF UNTRIPPED AND TRIPPED DECAY UNEXCITED DATA WITH PLUME CENTERLINE VELOCITY DECAY CORRELATION CURVE FOR $T_{j} / t_{0}$ VALUES OF 1.0 AND 2.3. $X / D_{j}, 9$. 


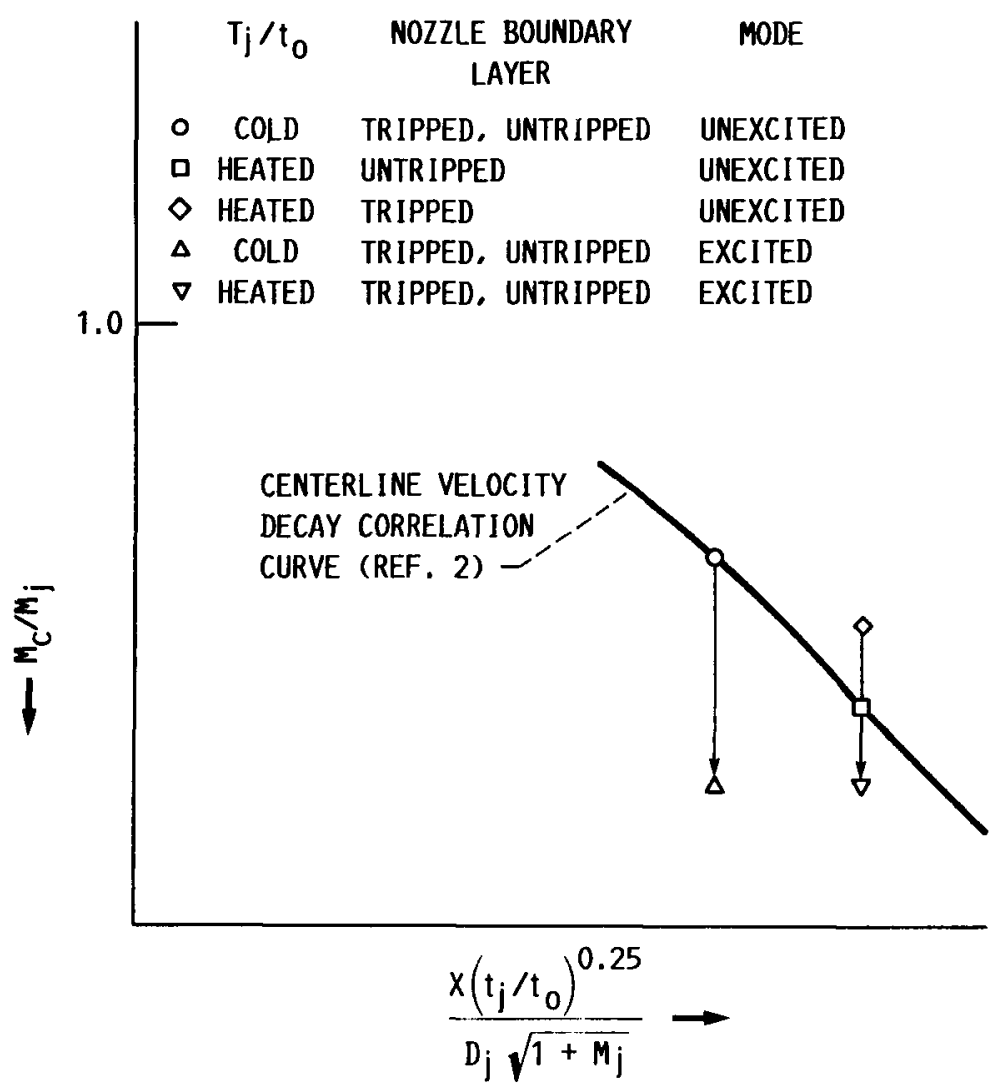

FIGURE 8. - SCHEMATIC SKETCH OF TYPICAL EFFECTS OF NOZZLE BOUNDARY LAYER TRIPPING ON COLD AND HEATED FLOW PLUME CENTERLINE MACH NUMBER DECAY WITH AND WITHOUT ACOUSTIC EXCITATION. 


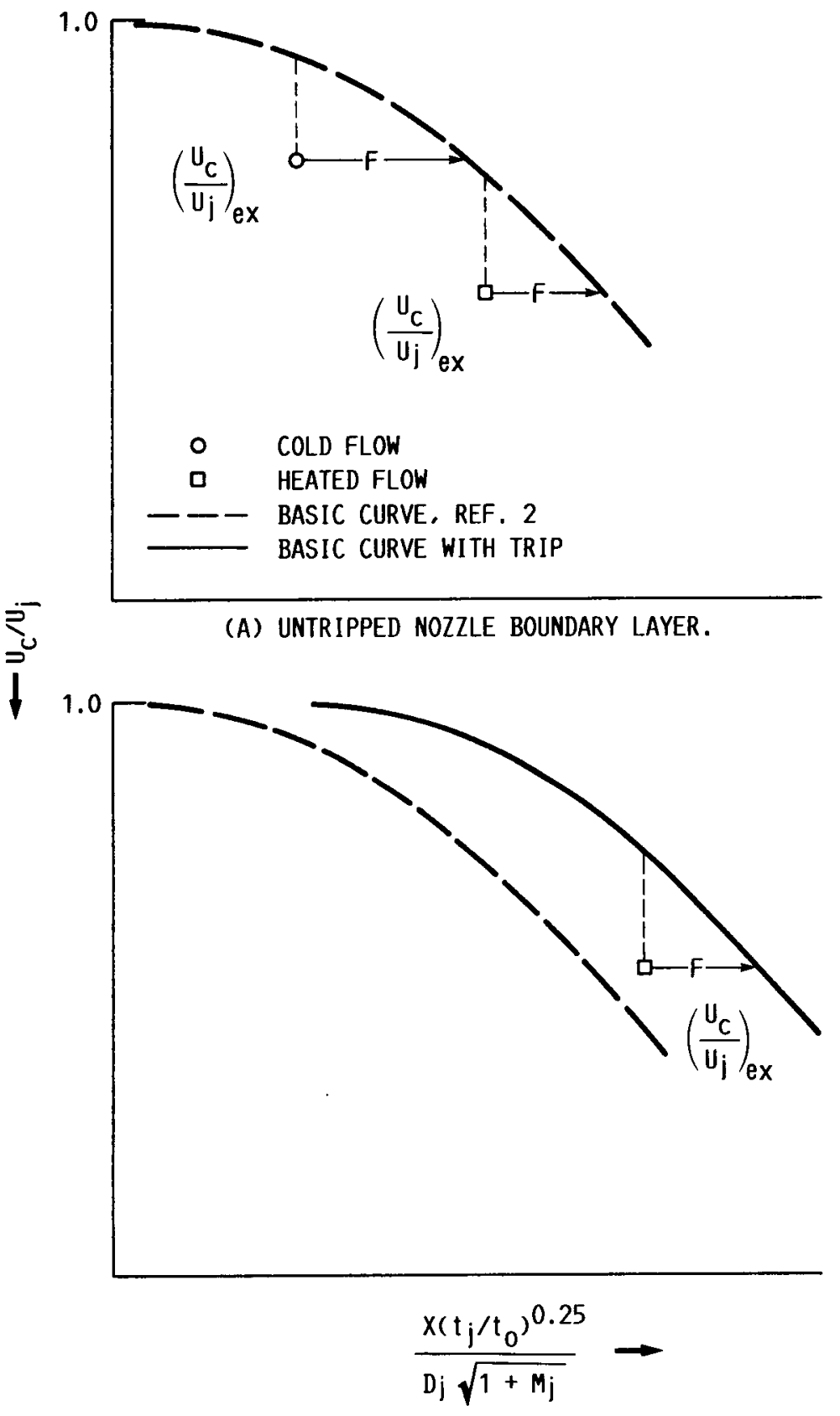

(B) TRIPPED NOZZLE BOUNDARY LAYER.

FIGURE 9. - DEFINITION OF CORRELATION PARAMETER F. 


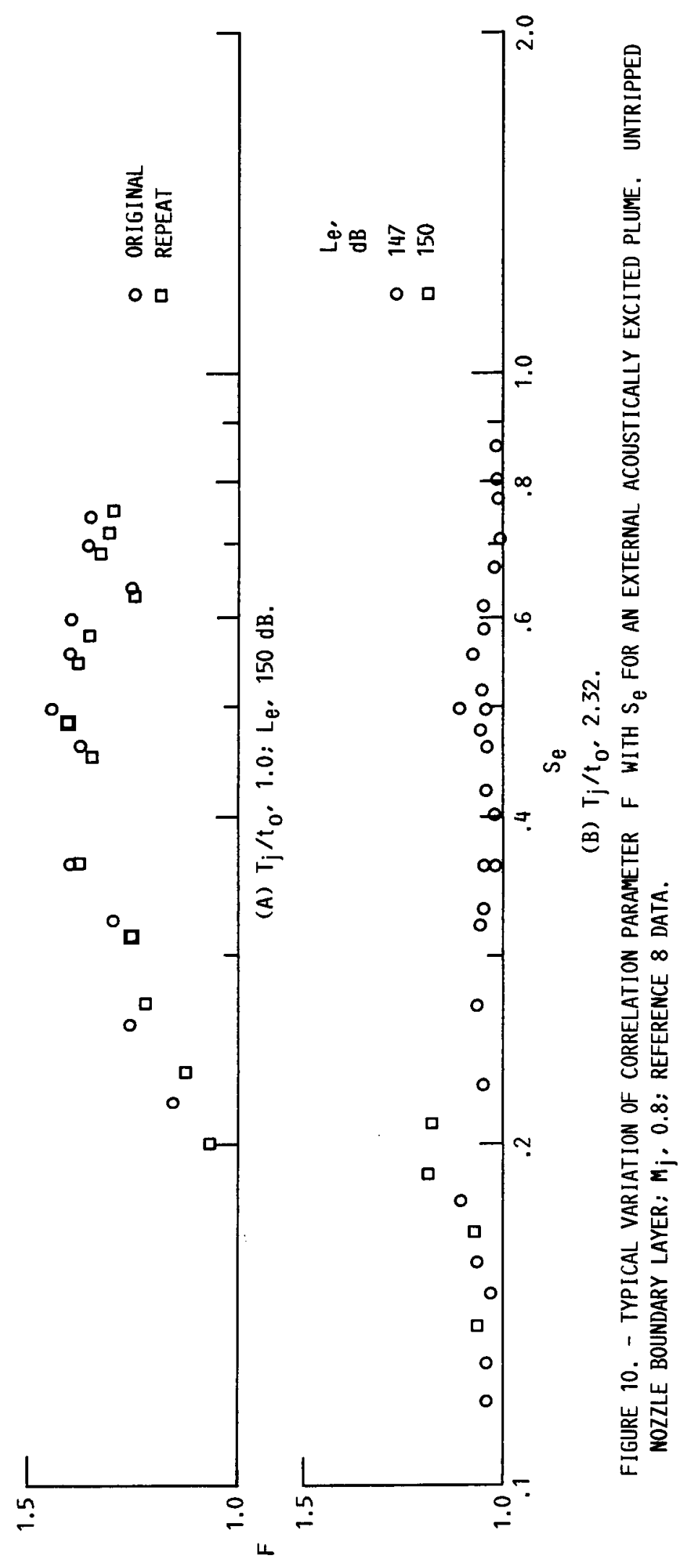




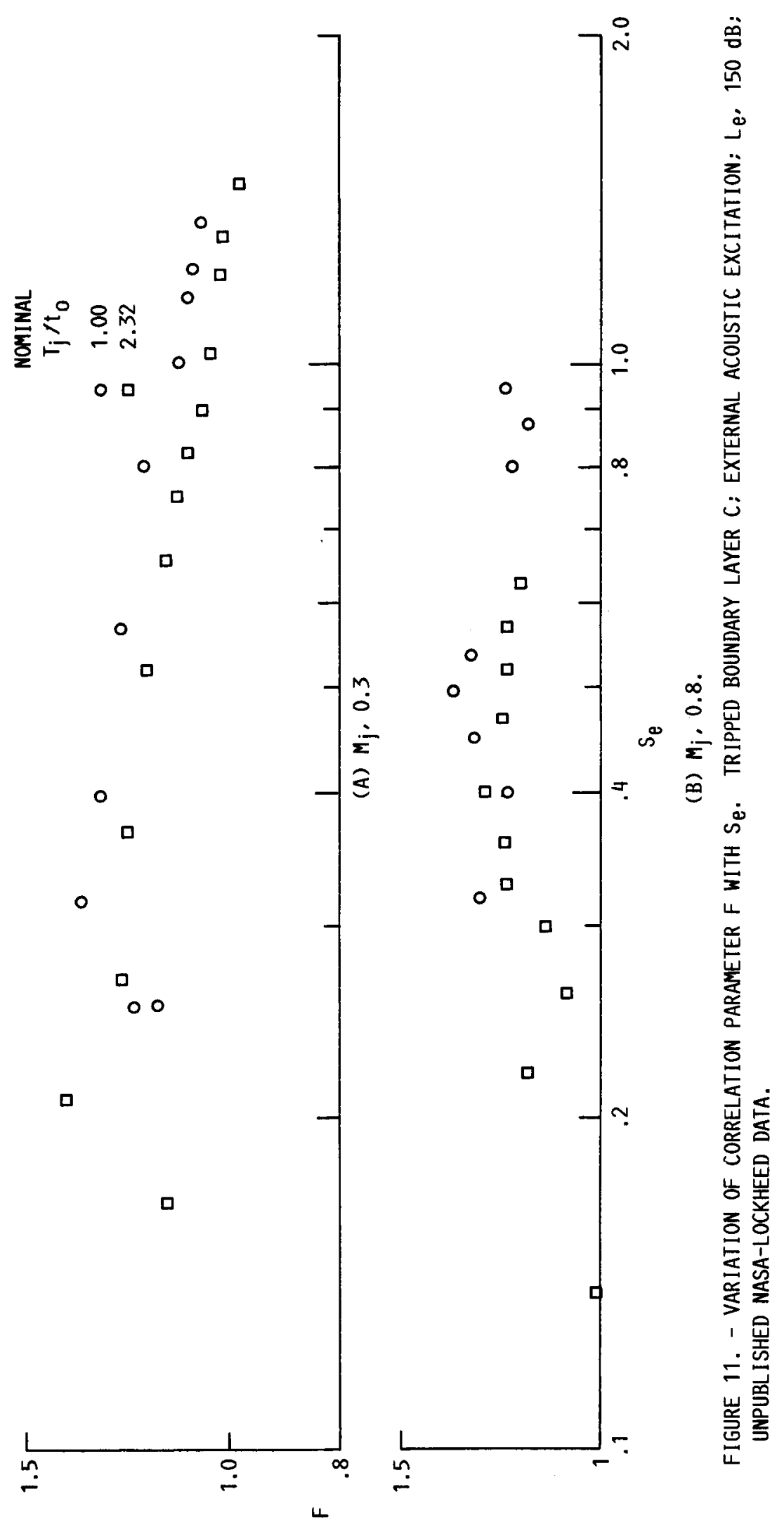




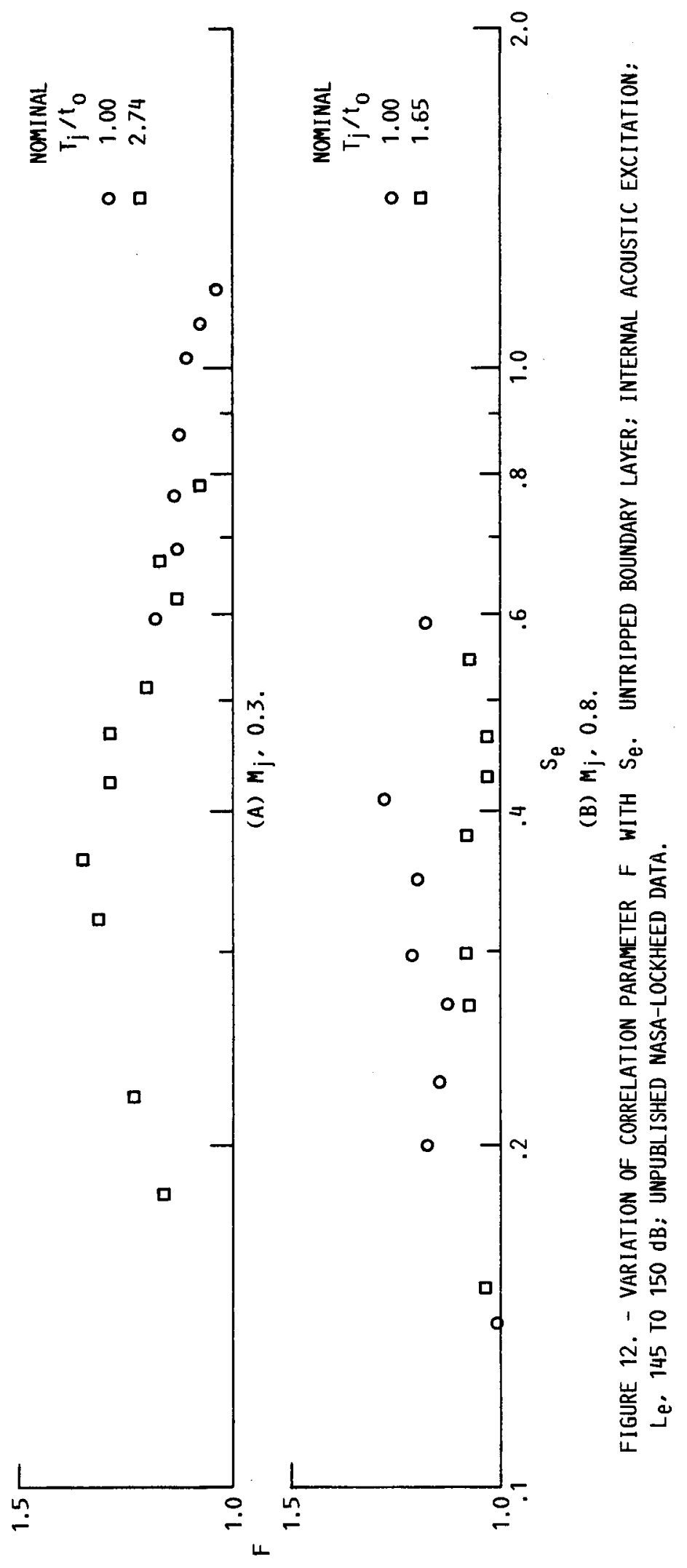



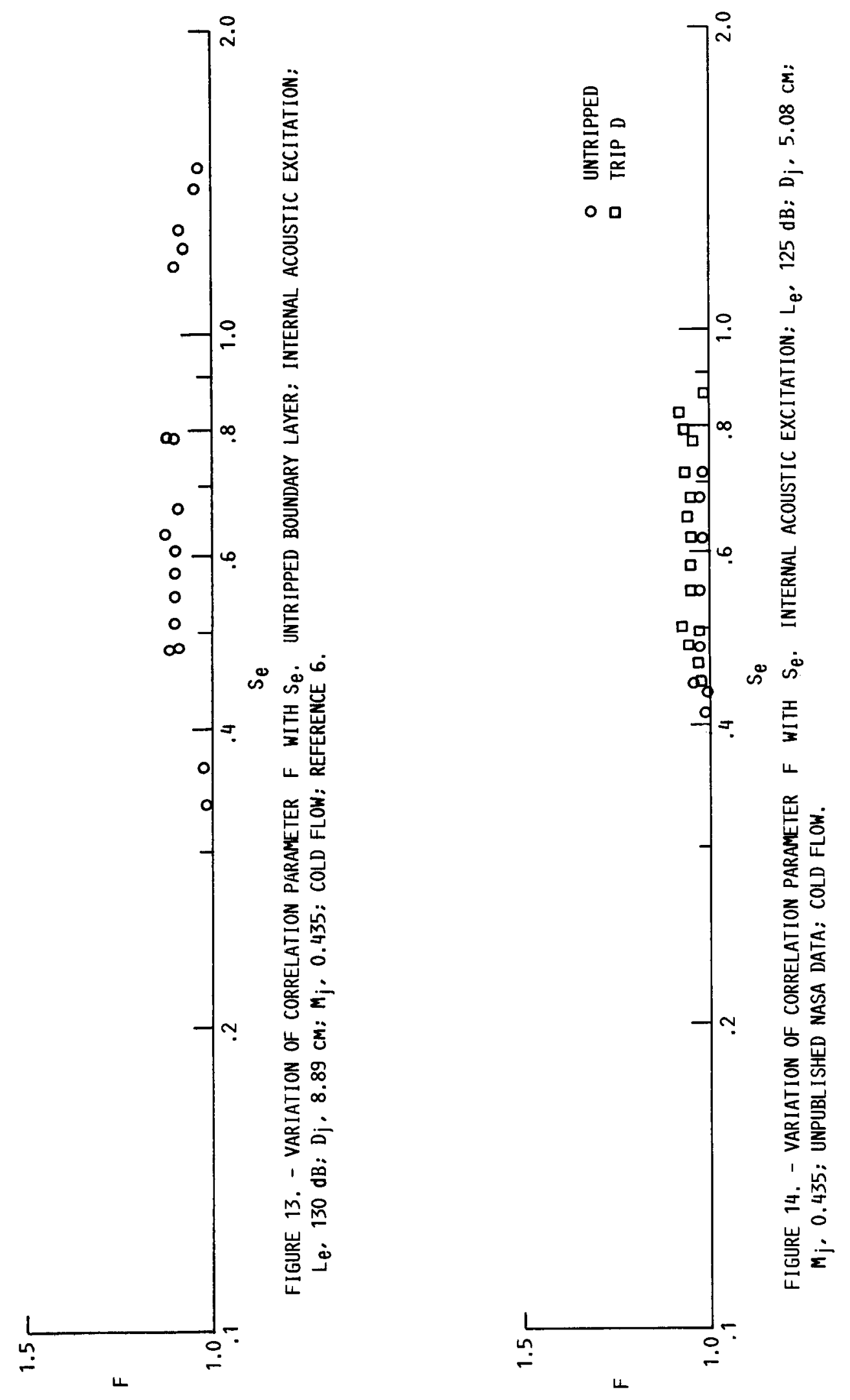


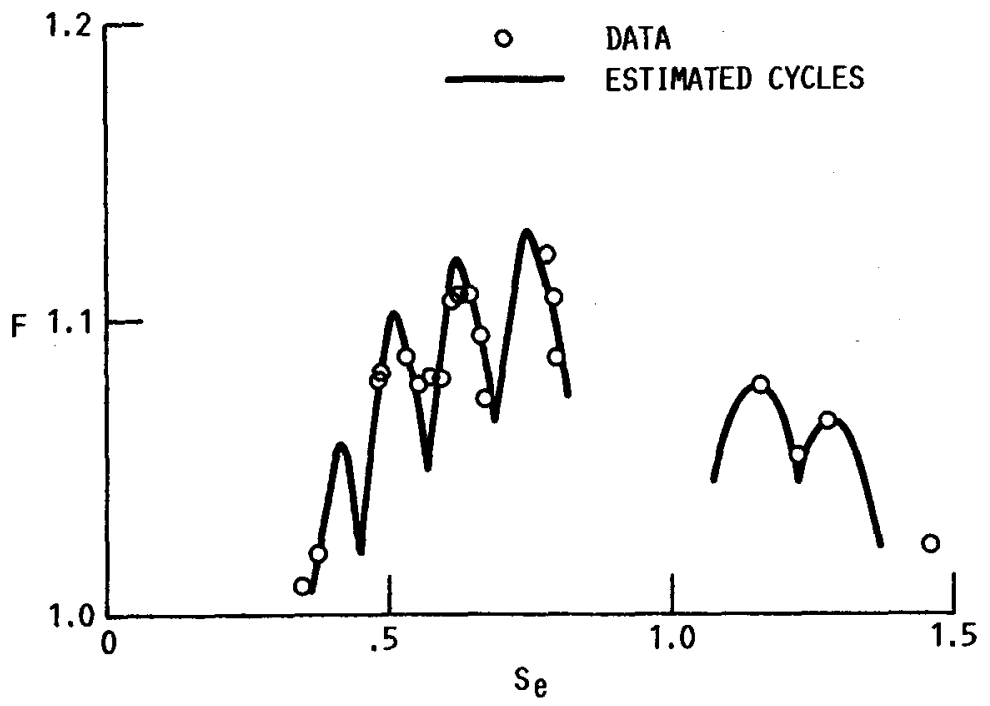

FIGURE 15. - PERIODIC NATURE OF $F$ VARITION WITH $S_{e}$ USING INTERNAL ACOUSTIC EXCITATION. UNTRIPPED BOUNDARY LAYER: $\mathrm{D}_{j}, 8.89 \mathrm{~cm} ; \mathrm{L}_{\mathrm{e}}, 130 \mathrm{~dB} ; \mathrm{M}_{j}, 0.435$; COLD FLOW: REFERENCE 6 DATA. 

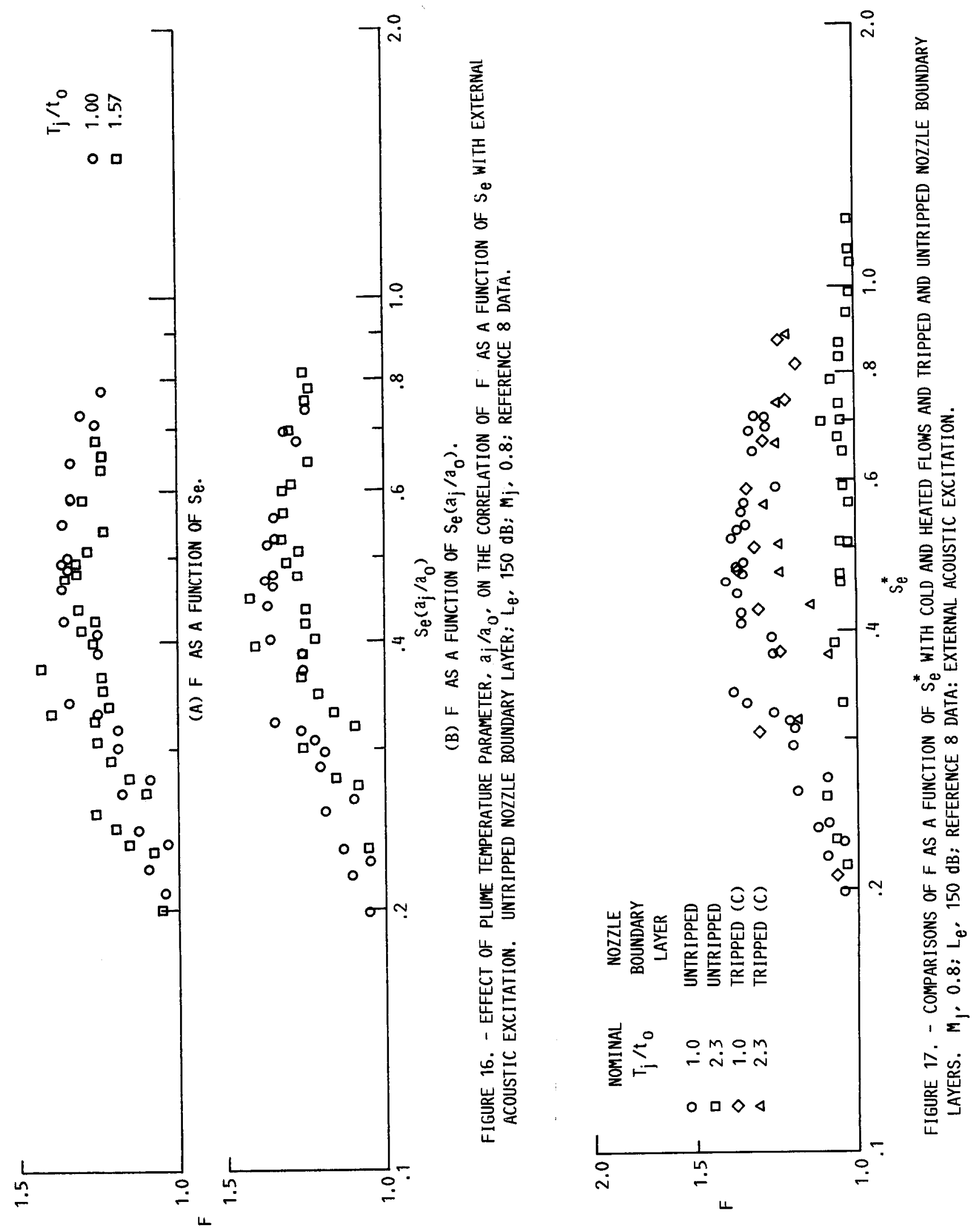

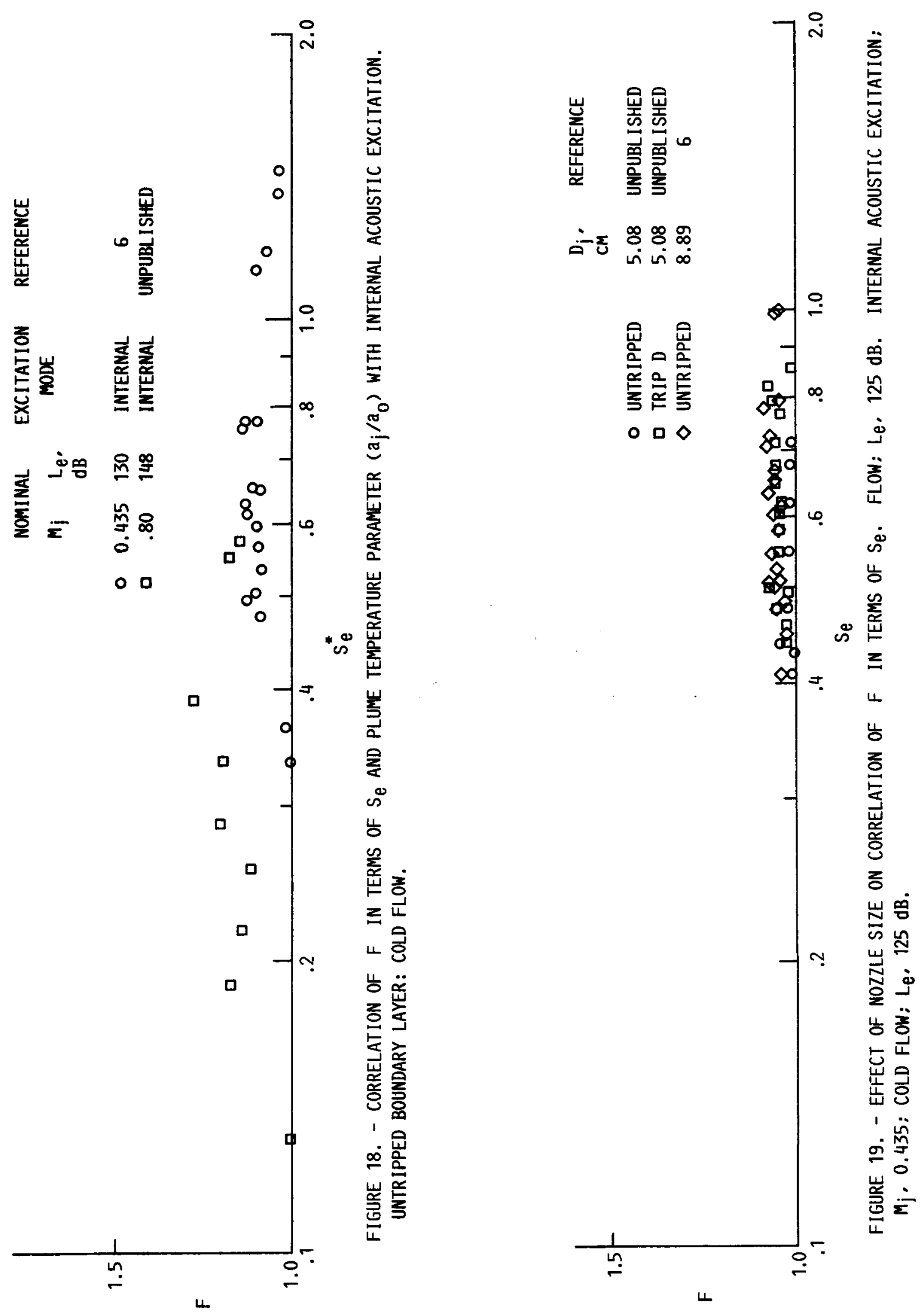


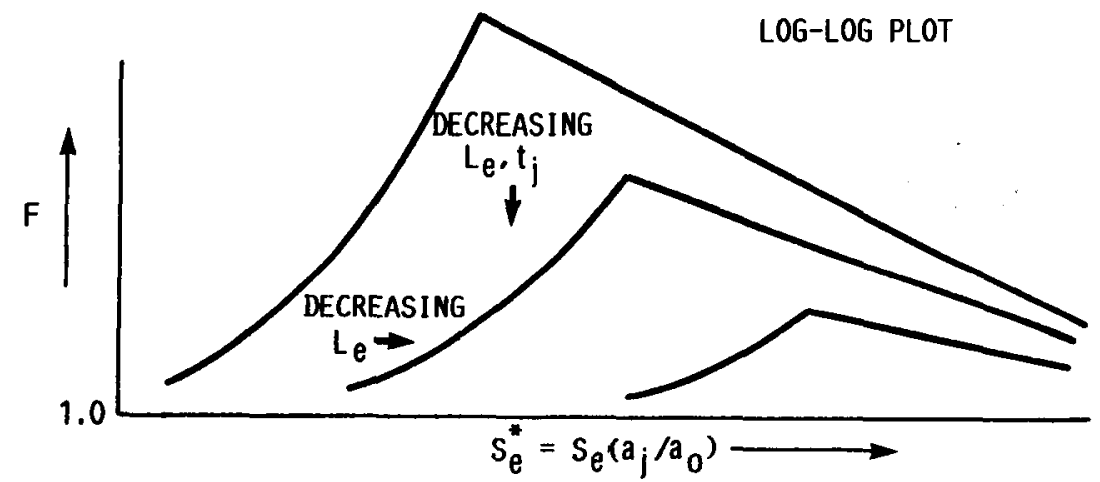

FIGURE 20. - SCHEMATIC SKETCH OF ACOUSTIC LEVEL AND TEMPERATURE EFFECTS ON PLUME CENTERLINE VELOCITY DECAY CORRELATION PARAMETER F. TURBULENT FLOW: UNTRIPPED NOZZLE BOUNDARY LAYER. 


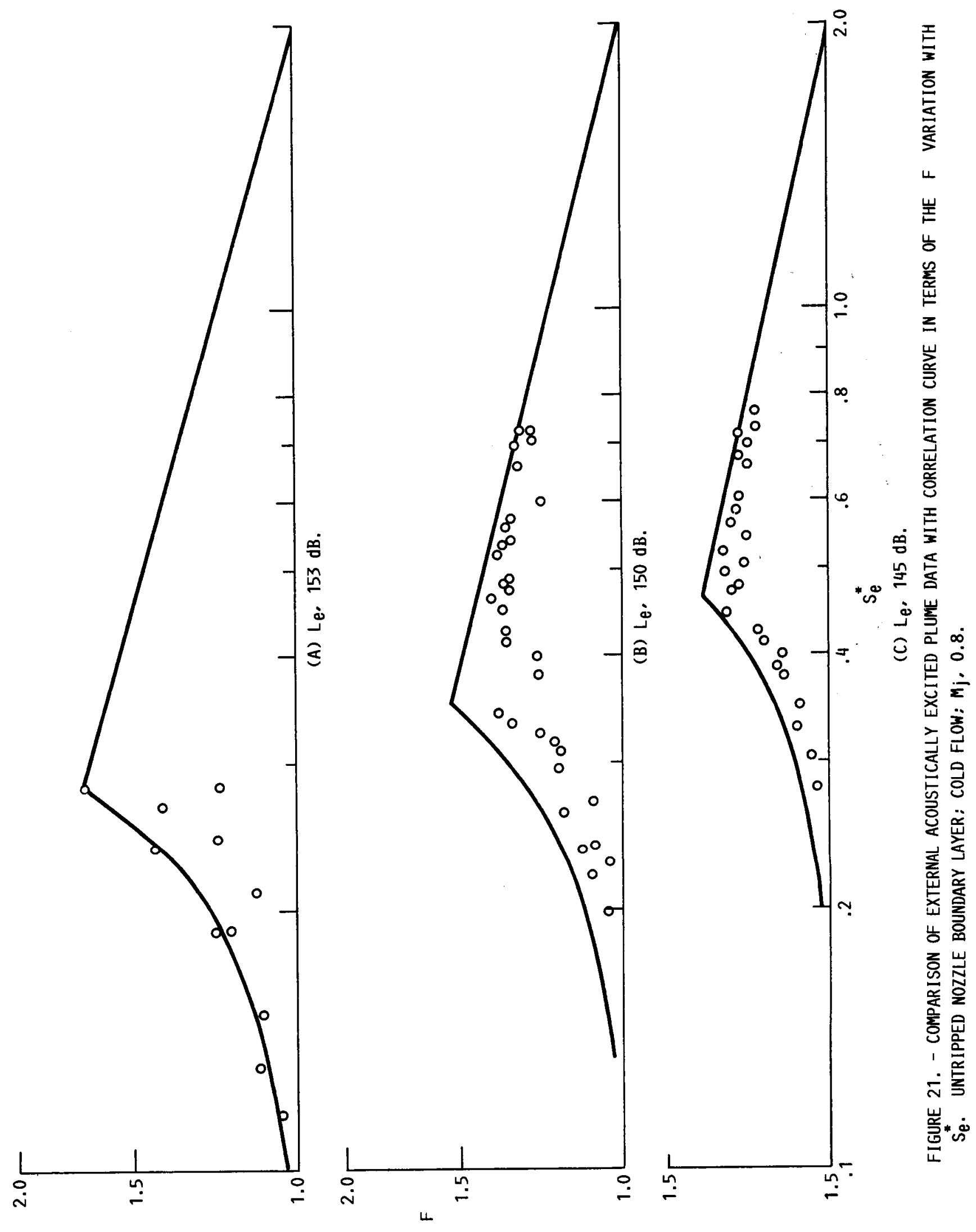



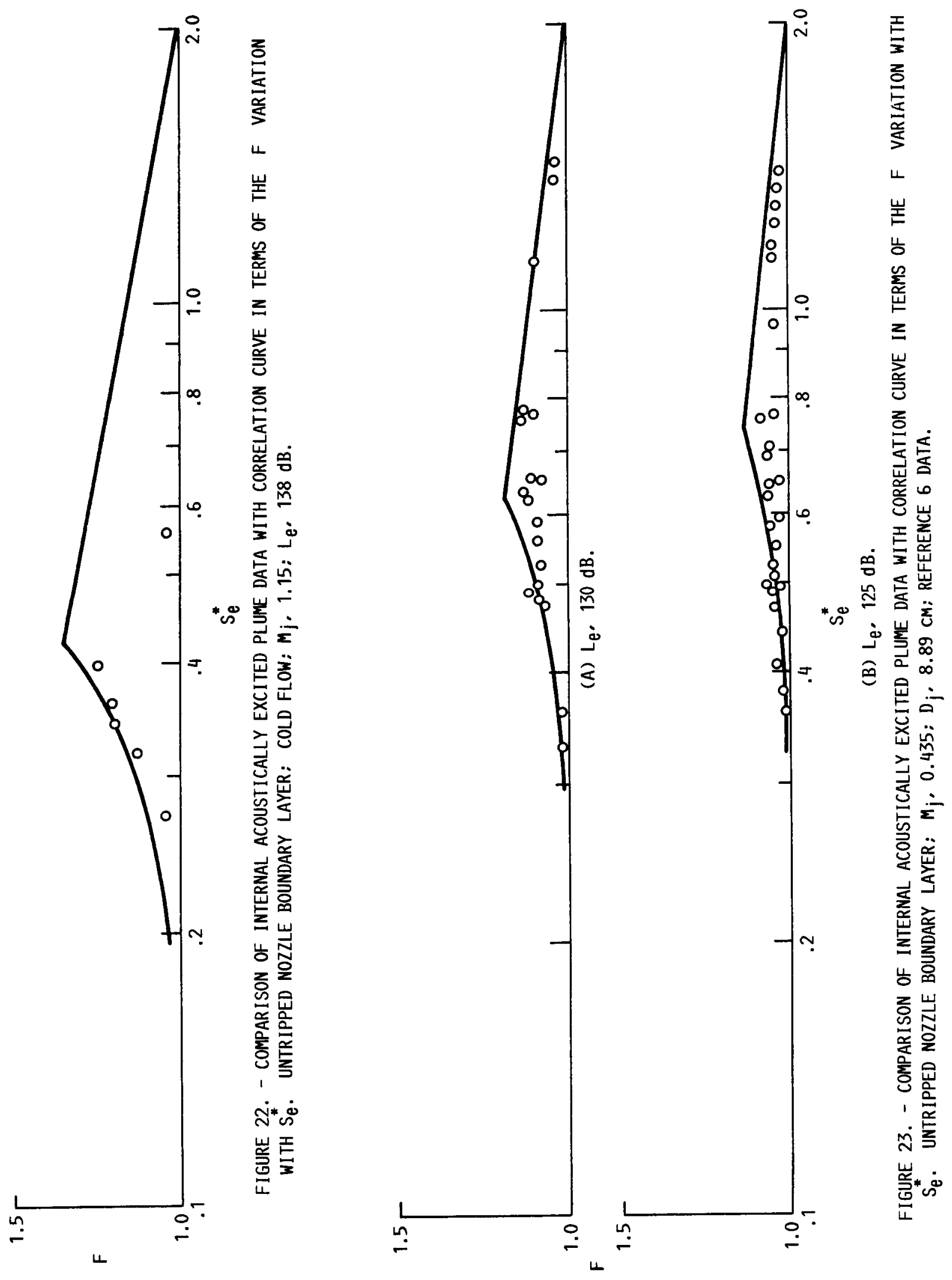


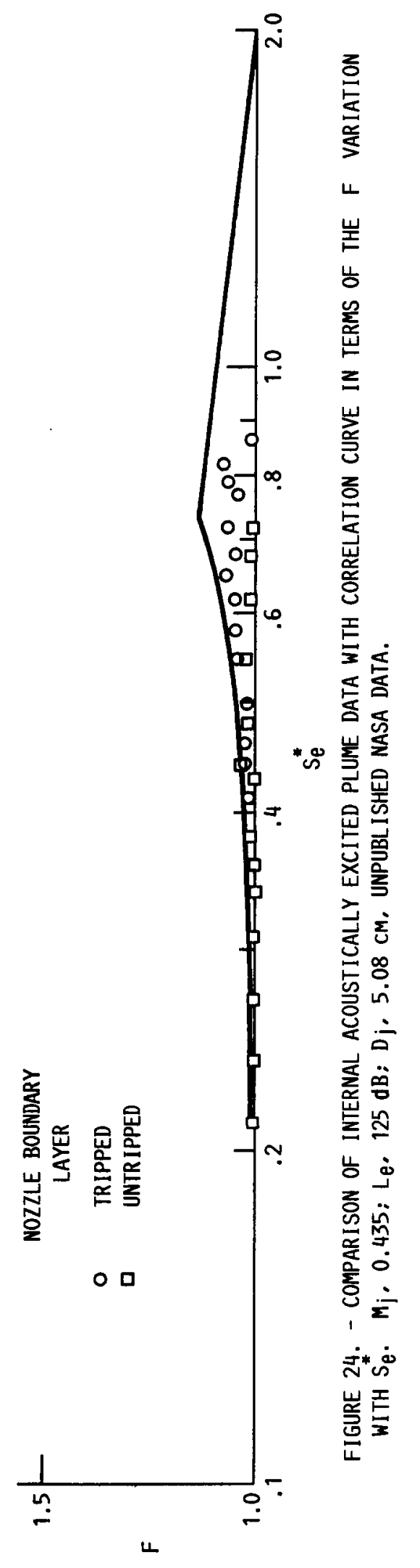




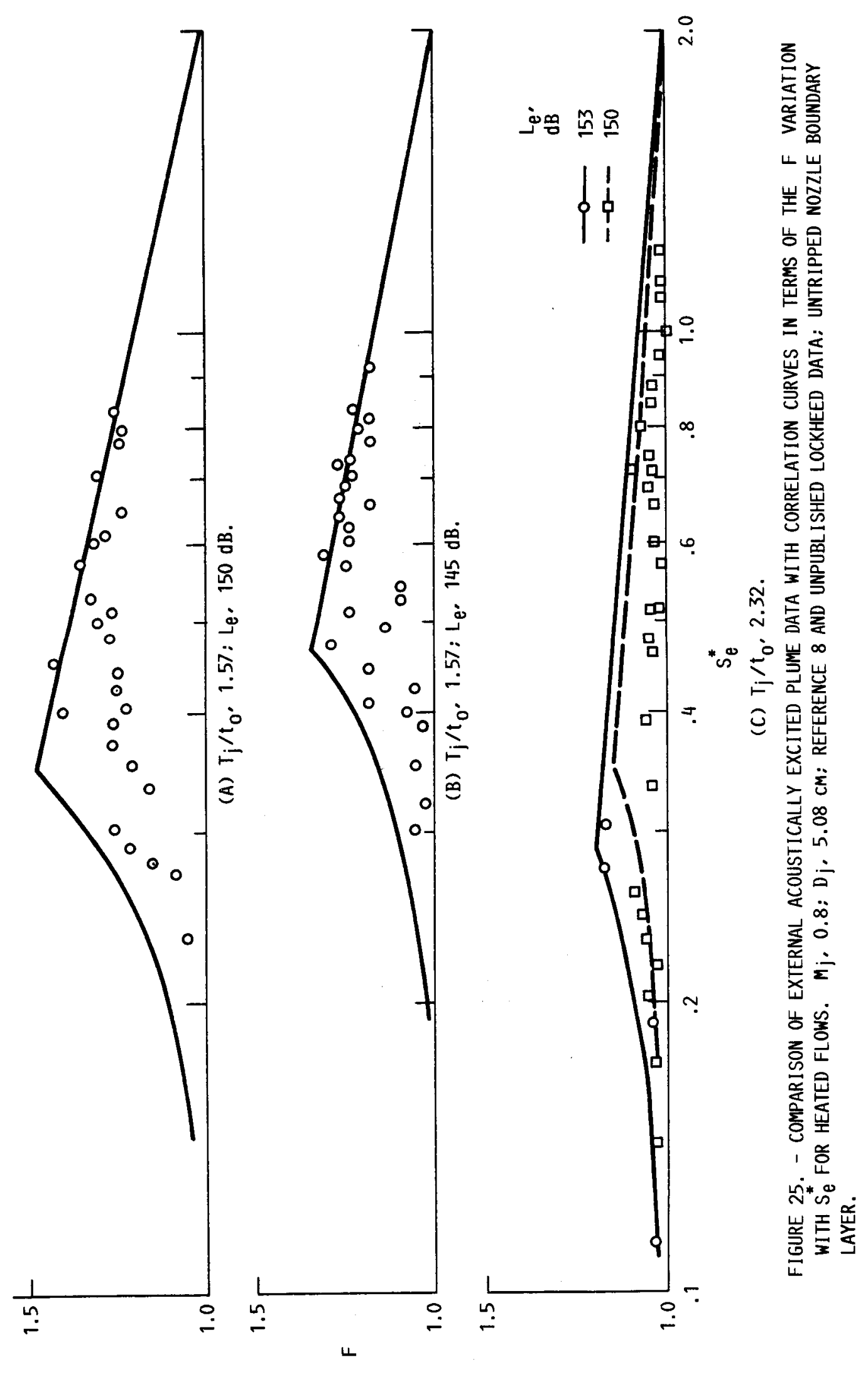




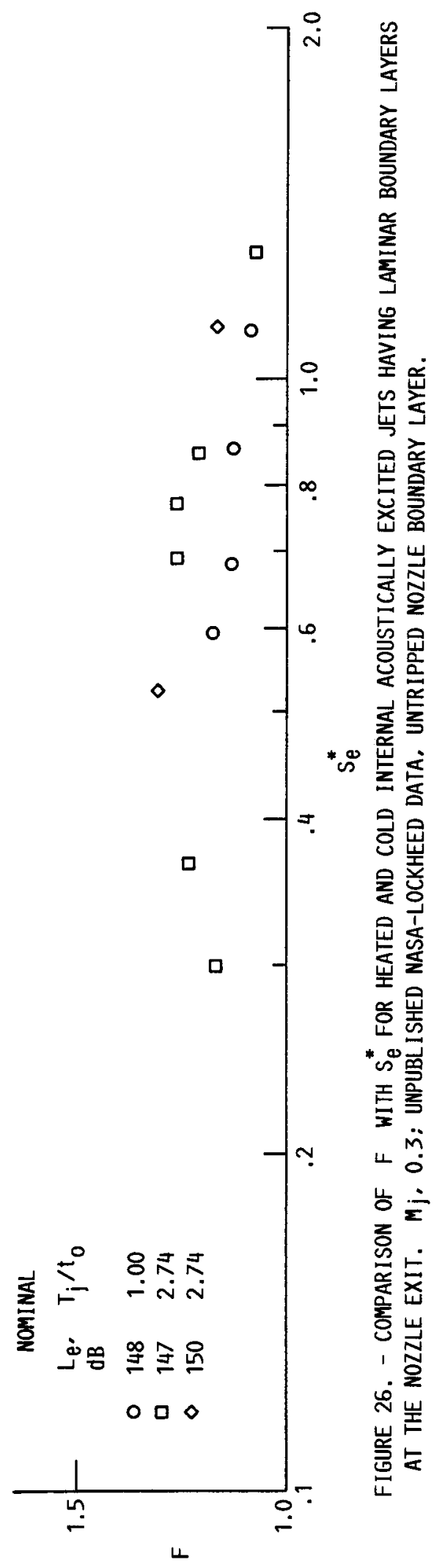




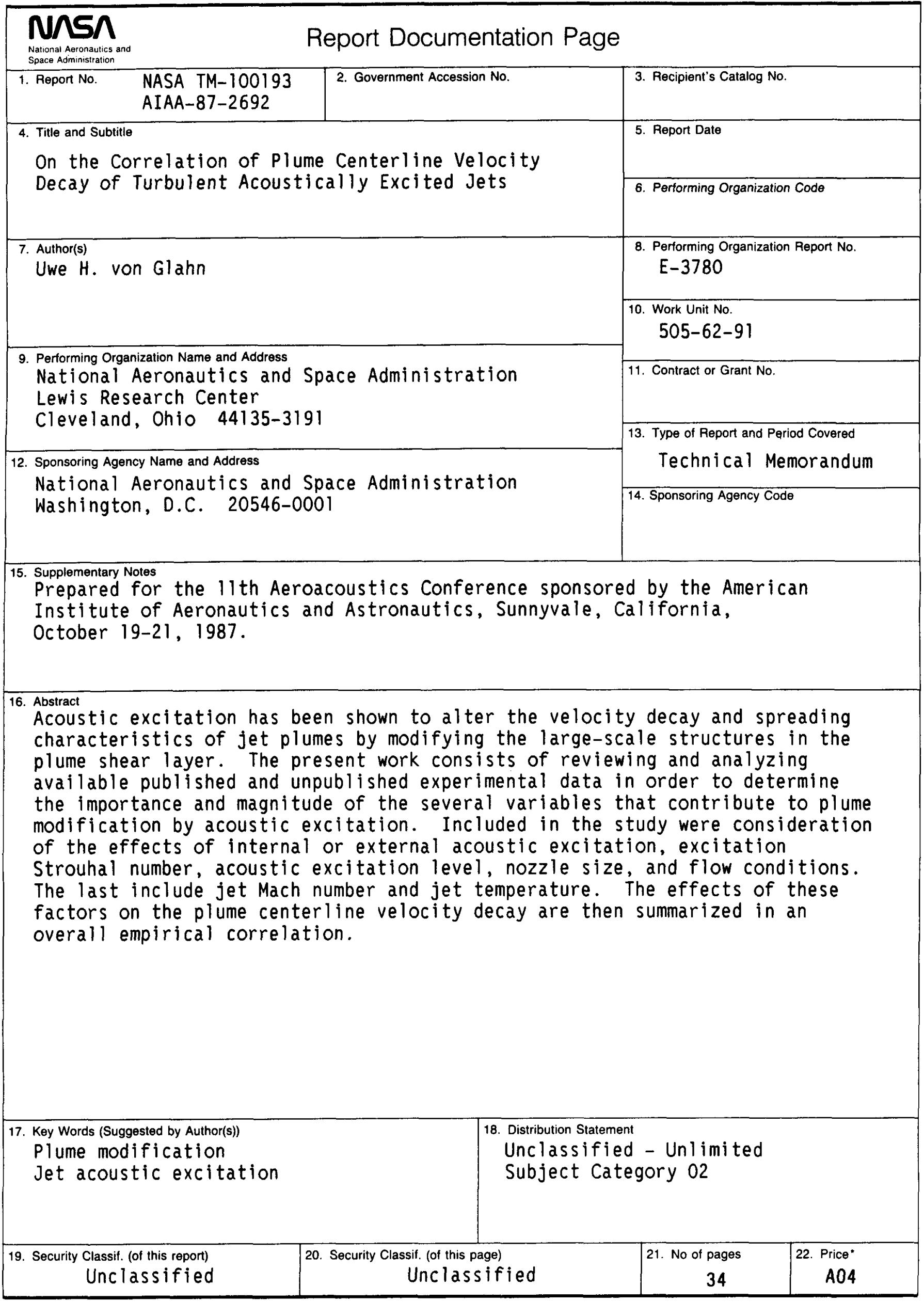

